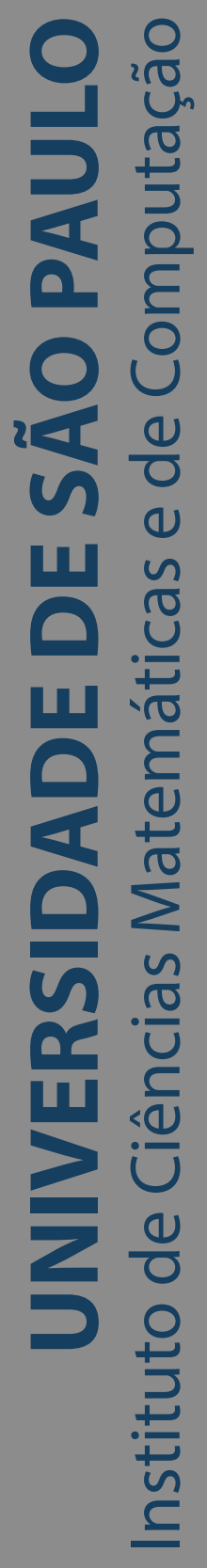

\title{
Cônicas em modelos físicos
}

\section{Luciano Santos Toniolo}

Dissertação de Mestrado do Programa de Mestrado Profissional em Matemática em Rede Nacional (PROFMAT) 

SERVIÇO DE PÓS-GRADUAÇÃO DO ICMC-USP

Data de Depósito:

Assinatura:

\section{Luciano Santos Toniolo}

\section{Cônicas em modelos físicos}

Dissertação apresentada ao Instituto de Ciências Matemáticas e de Computação - ICMC-USP, como parte dos requisitos para obtenção do título de Mestre em Ciências - Mestrado Profissional em Matemática em Rede Nacional. VERSÃO REVISADA Área de Concentração: Mestrado Profissional em Matemática em Rede Nacional

Orientador: Prof. Dr. Marcelo Rempel Ebert 
Ficha catalográfica elaborada pela Biblioteca Prof. Achille Bassi e Seção Técnica de Informática, ICMC/USP, com os dados inseridos pelo(a) autor(a)

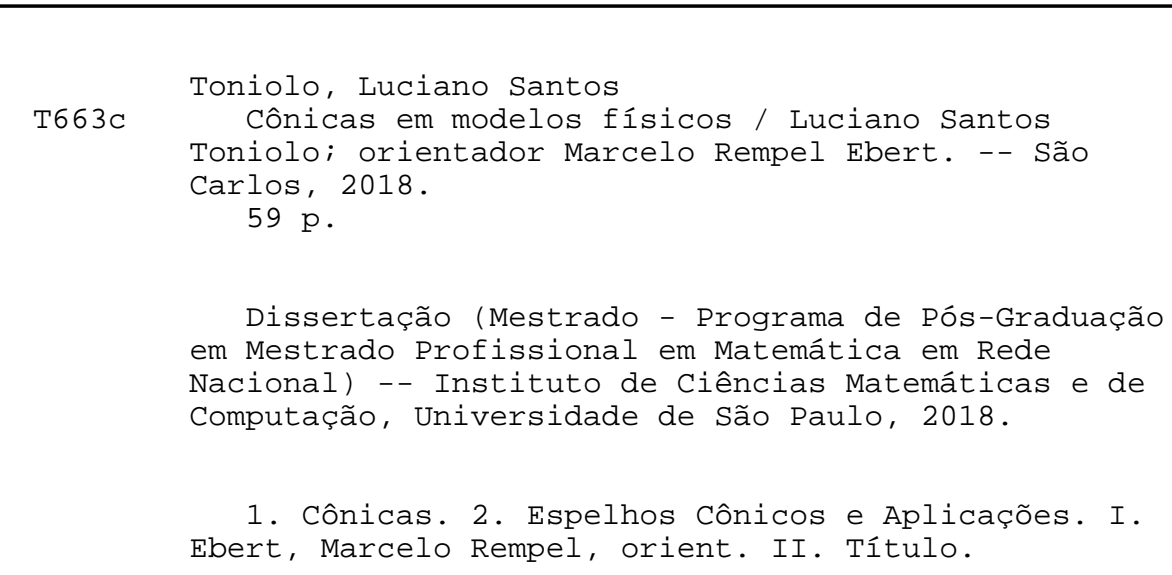

Bibliotecários responsáveis pela estrutura de catalogação da publicação de acordo com a AACR2: Gláucia Maria Saia Cristianini - CRB - 8/4938

Juliana de Souza Moraes - CRB - 8/6176 


\title{
Luciano Santos Toniolo
}

\section{Conics in physical models}

\author{
Master dissertation submitted to the Institute of \\ Mathematics and Computer Sciences - ICMC-USP, in \\ partial fulfillment of the requirements for the degree of \\ Mathematics Professional Master's Program. FINAL \\ VERSION \\ Concentration Area: Professional Master Degree \\ Program in Mathematics in National Network \\ Advisor: Prof. Dr. Marcelo Rempel Ebert
}

USP - São Carlos

July 2018 

Dedico este trabalho aos meus pais Marcos e Cristina, à minha irmã Karla e a minha noiva Michele, por tanta paciência, compreensão e incentivo à realização deste mestrado. 

Agradeço primeiramente à Deus pela minha vida, pelo Dom que me deu e pela força para superar todos os desafios surgidos ao longo desta caminhada.

Agradeço aos meus pais Marcos e Cristina e minha irmã Karla por todo o amor, incentivo, ajuda e paciência comigo ao longo da elaboração deste trabalho.

Agradeço a minha noiva Michele, pelo incentivo à realização deste curso, por ter acreditado em mim a todo momento, por toda a ajuda psicológica e por todo amor, carinho e compreensão mesmo durante as semanas mais difíceis.

Agradeço meu orientador Marcelo, por toda sua dedicação, paciência e por todos os seus ensinamentos que levarei em minha vida.

A todos vocês, minha eterna gratidão e carinho. 

"A mente que se abre a uma nova ideia, jamais voltará ao seu tamanho original."

(Albet Einstein) 



\section{RESUMO}

TONIOLO, L. S. Cônicas em modelos físicos. 2018. 59 p. Dissertação (Mestrado em Ciências - Mestrado Profissional em Matemática em Rede Nacional) - Instituto de Ciências Matemáticas e de Computação, Universidade de São Paulo, São Carlos - SP, 2018.

Este trabalho é um estudo realizado em torno das principais curvas cônicas estudadas por alunos do ensino básico: parábola, elipse e hipérbole. A ideia central do trabalho é a autosuficiência, pois apresentamos todas as ferramentas matemáticas necessárias para o entedimento desses entes e suas aplicações, desde os axiomas iniciais da geometria plana até as definições formais das cônicas e demonstrações de suas propriedades. Espera-se que uma pessoa não especializada em matemática, ao ler o trabalho, entenda toda a matemática no entorno das aplicações dessas cônicas.

Palavras-chave: Cônicas, Axiomas da Geometria, Espelhos Cônicos. 



\section{ABSTRACT}

TONIOLO, L. S. Conics in physical models. 2018. 59 p. Dissertação (Mestrado em Ciências Mestrado Profissional em Matemática em Rede Nacional) - Instituto de Ciências Matemáticas e de Computação, Universidade de São Paulo, São Carlos - SP, 2018.

This work is a study carried out around the main conic curves studied by elementary school students: parabola, ellipse and hyperbola. The main idea of this work is to be self-contained, starting from the basic axioms from the geometry and after we present formal definitions, properties and applications of conics in the everyday life. It is expected that a person that is not a specialist in mathematics, are able to read and understand all the mathematics in the surroundings of the applications of these conics.

Keywords: Conics, Axioms from Geometry, Conical Mirrors. 

Figura 1 - Representação de um ângulo (I). . . . . . . . . . . . . . . . . . 23

Figura 2 - Representação de um ângulo (II) . . . . . . . . . . . . . . . . 23

Figura 3 - Medida de um ângulo . . . . . . . . . . . . . . . . . 23

Figura 4 - Ângulos opostos pelo vértice . . . . . . . . . . . . . . . . 24

Figura 5 - Triângulos Congruentes . . . . . . . . . . . . . . . 25

Figura 6 - Retas Paralelas . . . . . . . . . . . . . . . 28

Figura 7 - Ângulos correspondentes em retas paralelas cortadas por uma transversal . . 29

Figura 8 - Triângulo Reto . . . . . . . . . . . . . . . . 30

Figura 9 - Coordenadas x e y do ponto P . . . . . . . . . . . 33

Figura 10 - Distância entre pontos do plano . . . . . . . . . . . . . . . . 34

Figura 11 - Parábola $x^{2}=4$ py . . . . . . . . . . . . . . . 36

Figura 12 - Parábola $y=a x^{2}+b x+c \ldots \ldots \ldots \ldots$. . . . . . . . . . . . .

Figura 13 - Elipse . . . . . . . . . . . . . . . . . . . 39

Figura 14 - Hipérbole . . . . . . . . . . . . . . . . . . . 41

Figura 15 - Reflexão da luz em superfície plana e esférica. . . . . . . . . . . . . . 44

Figura 16 - Reta t, reta tangente em P . . . . . . . . . . . . . . . 44

Figura 17 - Lei da reflexão na parábola. . . . . . . . . . . . . . . . . . 45

Figura 18 - Farol Parabólico . . . . . . . . . . . . . . . . . . 45

Figura 19 - Forno Solar . . . . . . . . . . . . . . . . . . . 46

Figura 20 - Antena Parabólica . . . . . . . . . . . . . . . . . 46

Figura 21 - Lei da reflexão na elipse. . . . . . . . . . . . . . . . . . . 47

Figura 22 - Movimento Elíptico dos Planetas . . . . . . . . . . . . . . . . 48

Figura 23 - Espelho Elíptico . . . . . . . . . . . . . . . . . . . . 49

Figura $24-$ Telescópio refletor . . . . . . . . . . . . . . . . . . . 50

Figura 25 - Observatório Monte Palomar (EUA) . . . . . . . . . . . . . . . . . . . . . . . . . . . 50

Figura 26 - Exemplo de Luminária $1 \ldots \ldots$. . . . . . . . . . . . 52

Figura 27 - Exemplo de Luminária $2 \ldots \ldots$. . . . . . . . . . . . 52

Figura 28 - Exemplo de Luminária $3 \ldots \ldots$. . . . . . . . . . . . . 52

Figura 29 - Exemplo de Luminária $4 \ldots \ldots$. . . . . . . . . . . . . . . . . . . . . . . . . . . . . 52

Figura 30 - Parabológrafo . . . . . . . . . . . . . . . . . 53

Figura 31 - Elaboração da Elipse . . . . . . . . . . . . . . . . . 54

Figura 32 - Mesa de Bilhar Mágica . . . . . . . . . . . . . . . . 55

Figura 33 - Demonstração do experimento: Mesa de Bilhar Mágica . . . . . . . . . . 55 
Figura $34-$ Hiperbológrafo $\ldots \ldots \ldots \ldots \ldots$ 
INTRODUÇÃO . . . . . . . . . . . . . . . . . 19

NOÇÕES BÁSICAS dE GEOMETRIA . . . . . . . . . . . . . . . 21

$2.1 \quad$ Axioma de incidência e ordem . . . . . . . . . . . . . 21

$2.2 \quad$ Axiomas sobre medição de segmentos . . . . . . . . . . . . . 22

2.3 Axiomas sobre medição de ângulos . . . . . . . . . . . . . . . 22

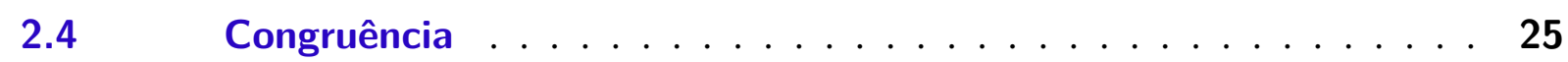

$2.5 \quad$ Axioma das Paralelas . . . . . . . . . . . . . . . 27

$2.6 \quad$ Teorema de Pitágoras . . . . . . . . . . . . . . 30

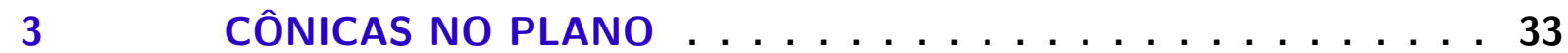

$3.1 \quad$ Coordenadas no plano . . . . . . . . . . . . . 33

3.1.1 Distância entre pontos no plano . . . . . . . . . . . . . . . 34

3.2 Definição e tratamento algébrico das cônicas . . . . . . . . . . 35

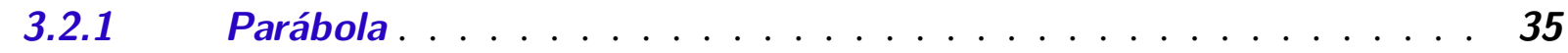

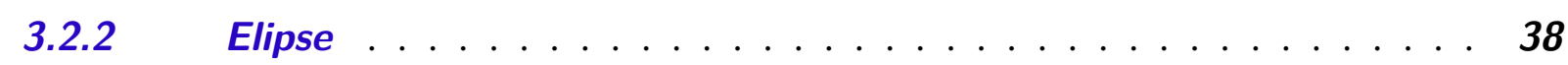

3.2.3 Hipérbole ...................... 39

4 ESPELHOS CÔNICOS E APLICAÇÕES . . . . . . . . . . . . 43

4.1 Óptica Geométrica e Reflexão . . . . . . . . . . . . . . . . . 43

$4.2 \quad$ Espelho Parabólico . . . . . . . . . . . . . . . . 44

4.2.1 Farol Parabólico . . . . . . . . . . . . . . . . . 45

$4.2 .2 \quad$ Forno Solar . . . . . . . . . . . . . . . . . . . 45

4.2.3 Antena Parabólica . . . . . . . . . . . . . . . . . 46

$4.3 \quad$ Espelho Elíptico . . . . . . . . . . . . . . . . 47

4.3.1 Movimento dos Planetas . . . . . . . . . . . . . . . . 48

4.3.2 Aparelhos na área da saúde . . . . . . . . . . . . . . 49

$4.4 \quad$ Espelho Hiperbólico . . . . . . . . . . . . . . . . . . . . . . 49

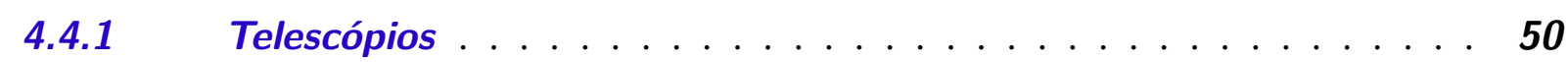

5 PROPOSTA PEDAGÓGICA VIA PROJETO . . . . . . . . . . . 51

$5.1 \quad$ Estudo das Parábolas . . . . . . . . . . . . . . . 51

5.1 .1 Motivação com luminárias . . . . . . . . . . . . . . . . 51

5.1 .2 Construção geométrica segundo a definição . . . . . . . . . . 53 
5.1.3 Propriedades e aplicações da Parábola . . . . . . . . . . . . 53

$5.2 \quad$ Estudo das Elipses . . . . . . . . . . . . . . . . . . . 54

5.2.1 Construção geométrica segundo a definição . . . . . . . . . 54

5.2.2 Projeto mesa de bilhar mágica . . . . . . . . . . . . . 54

5.2.3 Explicação Matemática e Aplicações . . . . . . . . . . . . . 55

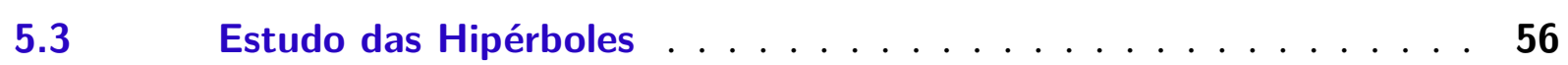

5.3.1 Construção geométrica segundo a definição . . . . . . . . 56

5.3.2 Propriedades e aplicações da Hipérbole . . . . . . . . . . . 57

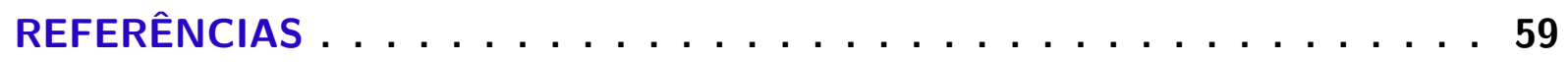




\section{1}

\section{INTRODUÇÃO}

Ao pesquisarmos sobre as aplicações das principais curvas cônicas estudadas por alunos do ensino básico, encontramos uma grande gama de informações, sobretudo na internet. Porém, dificilmente essas informações estão bem descritas matematicamente, muitas vezes com demonstrações imprecisas ou incompletas. Observando isso, resolvemos fazer um trabalho o mais completo possível, onde espera-se que uma pessoa não especializada em matemática, ao ler o trabalho, entenda toda a matemática no entorno das aplicações dessas cônicas, entre elas parábola, elipse e hipérbole.

Para que este trabalho torne-se autossuficiente, ou seja, uma pessoa quando o ler, compreenda todos os possíveis porquês que possam vir a aparecer. Vimos a necessidade de montar um forte alicerce geométrico que sustentará as principais demonstrações a respeito das propriedades das cônicas. O capítulo 2 destinado a geometria plana, começa da maneira mais elementar possível, com os axiomas básicos da geometria euclidiana e com definições de elementos simples na matemática, como por exemplo ângulo. Com o auxílio desses axiomas e das definições, provaremos ao longo deste capítulo, todas proposições necessárias que serão utilizadas para concluir o estudo sobre as propriedades das cônicas.

No ensino médio, muito provavelmente um aluno aprenderá as equações reduzidas das principais cônicas: parábola, elipse e hipérbole. Contudo, na maioria das vezes, também não é explicado formalmente porque a representação gráfica dessas equações coincidem com as cônicas. Acreditamos que esse tipo de prática desmotive o aluno, pois, para o aluno as informações irão vir "jogadas"como se fossem mágicas. Diante desse cenário, o capítulo 3 é destinado ao estudo das cônicas, associando as definições geométricas que elas possuem com suas equações algébricas. Esse capítulo também começa da maneira mais básica possível, falando de coordenadas no plano, para que, com o auxílio do capítulo de geometria plana, as cônicas possam ser descritas e suas equações reduzidas sejam deduzidas de maneira precisa.

Após as cônicas já estarem definidas e termos uma base geométrica e analítica delas, no 
capítulo 4 falaremos sobre o objetivo principal do trabalho, que são as propriedades especiais que as cônicas possuem, que fazem com que tenham várias aplicações no nosso dia-a-dia. Essas propriedades serão demonstradas da maneira mais precisa possível, e com elas em mãos, descreveremos algumas das aplicações dessas fantásticas curvas.

No capítulo 5 faremos uma proposta pedagógica sobre cônicas para ser realizada junto com alunos do terceiro ano do ensino médio. Numa primeira etapa, a partir das definições geométricas das cônicas, constrói-se a representação gráfica das mesmas no plano. Em particular, os alunos realizam a confecção de um objeto elíptico, onde, claramente a propriedade primordial de uma elipse fica evidenciada. Por fim, seguindo o Capítulo 4, as principais propriedades e aplicações das mesmas são discutidas.

Acreditamos que essa proposta, motive os alunos ao estudo das cônicas, e quem sabe, de toda a matemática, já que dessa maneira verão uma utilidade da matemática no dia-a-dia que, dificilmente, imaginavam que estavam relacionadas às cônicas. 


\section{NOÇÕES BÁSICAS DE GEOMETRIA}

Neste capítulo, seguindo a referência (BARBOSA, 1995), veremos algumas noções básicas de geometria plana, que serão ferramentas a serem utilizadas no estudo das cônicas em modelos físicos, que é o objetivo deste projeto.

\subsection{Axioma de incidência e ordem}

As figuras elementares, no plano, são os pontos e as retas. O plano é constituído de pontos e as retas são subconjuntos distinguidos de pontos no plano.

Axioma 1. Qualquer que seja a reta, existem pontos que pertencem à reta, e pontos que não pertencem a reta.

Axioma 2. Dados dois pontos distintos, existe uma única reta que contém esses pontos.

Axioma 3. Dados três pontos de uma reta, um e apenas um deles se localiza entre os outros dois.

Definição 1. O conjunto constituído por dois pontos $A$ e $B$ e por todos os pontos que se encontram entre $A$ e $B$, é chamado de segmento $A B$. Os pontos $A$ e $B$ são denominados de extremos ou extremidades do segmento.

A figura plana mais simples, constituída por segmentos é o triângulo que é formado por três pontos que não pertencem a uma mesma reta e pelos três segmentos formados por esses pontos. Os três pontos são chamados vértices do triângulo e os segmentos, lados do triângulo.

Definição 2. Se $A$ e $B$ são pontos distintos, o conjunto de pontos constituídos pelos pontos do segmento $A B$ e pelos pontos $C$ tais que $B$ esteja entre $A$ e $C$, é chamado de semirreta de origem $A$ contendo o ponto $B$ e é representado por $S_{A B}$. 
Considere uma reta $m$ e dois pontos $A$ e $B$ que não pertencem a essa reta. Diremos que $A$ e $B$ estão num mesmo lado da reta $m$ se o segmento $A B$ não a intercepta.

Definição 3. Sejam $m$ uma reta e $A$ um ponto que não pertence a $m$. O conjunto constituído por $m$ e por todos os pontos $B$ tais que $A$ e $B$ estão num mesmo lado da reta $m$ é chamado de semiplano determinado por $m$ contendo $A$ e será representado por $P_{m A}$.

\subsection{Axiomas sobre medição de segmentos}

Axioma 4. A todo par de pontos do plano corresponde um número maior ou igual a zero. Este número é zero, se e só se, esses pontos são coincidentes.

O número a que se refere esse axioma é chamado de distância entre os pontos ou é referido como o comprimento do segmento determinado por esses pontos.

Axioma 5. Os pontos de uma reta podem ser sempre colocados em correspondência biunívoca com os números reais, de modo que a diferença entre esses dois números meça a distância entre os pontos correspondentes.

Este axioma poderia receber o nome de "régua infinita", pois ao estabelecermos a correspondência entre os números reais e os pontos da reta, a reta torna-se como uma régua infinita, que pode ser usada para medir o comprimento dos segmentos nela contida.

Ao aplicarmos este axioma, o número que corresponde a um ponto da reta é denominado coordenada daquele ponto.

Assim, se $a$ e $b$ são as coordenadas dos pontos $A$ e $B$, indicaremos o comprimento do segmento $A B$ por $\overline{A B}$. Portanto, de acordo com o axioma $5, \overline{A B}=|b-a|$.

\subsection{Axiomas sobre medição de ângulos}

Definição 4. Chamamos de ângulo a figura formada por duas semirretas de mesma origem.

As semirretas são chamadas de lados do ângulo, e a origem comum de vértice do ângulo. Um ângulo formado por duas semirretas distintas de uma mesma reta é chamado de ângulo raso.

Há várias maneiras diferentes de representar um ângulo. Na Figura 1 o ângulo pode ser representado por $\hat{A}$, por $B \hat{A} C$ ou $C \hat{A} B$. Ao utilizar $B \hat{A} C$ ou $C \hat{A} B$ a letra que indica o vértice aparece entre as outras duas, as quais representam pontos das semi-retas que formam o ângulo. Também é comum a utilização de letras gregas para representar um ângulo. Neste caso é conveniente escrever a letra que representa o ângulo próximo ao seu vértice, como indicado na Figura 2. 


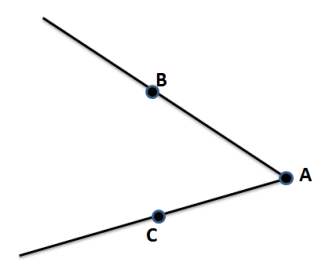

Figura 1 - Representação de um ângulo (I).

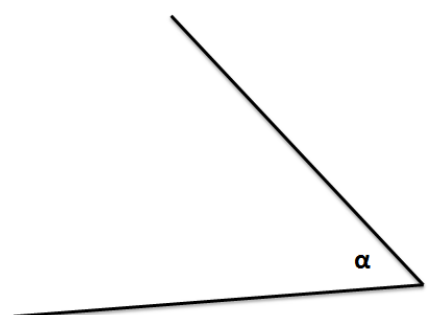

Figura 2 - Representação de um ângulo (II).

Axioma 6. Todo ângulo tem uma medida maior ou igual a zero. A medida do ângulo é zero se e somente se, as duas retas forem coincidentes.

Definição 5. Diremos que uma semirreta divide um semiplano se ela estiver contida no semiplano e sua origem for um ponto da reta que o determina.

Axioma 7. É possível colocar em correspondência biunívoca, os números reais entre zero e 180 e as semirretas de mesma origem que dividem um dado semiplano, de modo que a diferença entre esses números seja a medida do ângulo formado pelas semirretas correspondentes.

Ao fazer tal correspondência, chamamos o número que corresponde a uma dada semirreta de coordenada da semirreta. Na Figura 3 abaixo a semirreta $O A$ tem coordenada 60, a semirreta $O B$ tem coordenada 125 . De acordo com o axioma 7 a medida do ângulo $A \hat{O} B$ é $125-60=65$. Do mesmo modo, se $a$ e $b$ forem as coordenadas dos lados do ângulo $A \hat{O} B$, então $|a-b|$ é a medida deste ângulo. Observe que as semirretas que formam um ângulo raso são sempre numeradas por 0 e 180 , sendo a medida de tais ângulos sempre $180^{\circ}$.

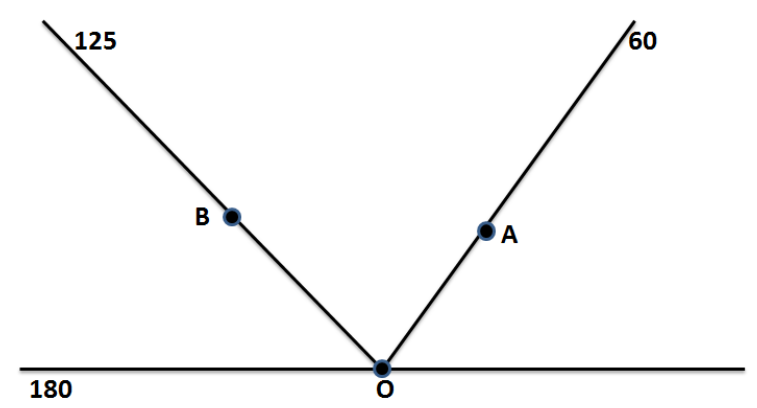

Figura 3 - Medida de um ângulo 
Quando duas retas distintas se interceptam, formam-se quatro ângulos. Os ângulos $A \hat{O} B$ e DÔC são opostos pelo vértice. Do mesmo modo os ângulos $A \hat{O} D$ e $B \hat{O} C$. Como indicado na figura abaixo.

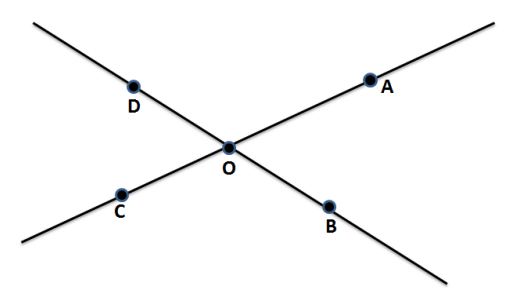

Figura 4 - Ângulos opostos pelo vértice

Proposição 1. Ângulos opostos pelo vértice tem a mesma medida.

Demostração: Notemos que

$$
A \hat{O} B+A \hat{O} D=180^{\circ}
$$

$\mathrm{e}$

$$
D \hat{O} C+A \hat{O} D=180^{\circ}
$$

Subtraindo a equação (2.2) de (2.1), temos

$$
A \hat{O} B-D \hat{O} C=0
$$

desse modo, mostramos que os ângulos opostos pelo vértice $A \hat{O} B$ e $D \hat{O} C$ tem a mesma medida.

Definição 6. Um ângulo cuja medida é $90^{\circ}$ é chamado de ângulo reto.

Quando duas retas se interceptam, se um dos quatro ângulos formados é reto, todos os outros serão. Nessa situação diremos que as retas são perpendiculares.

Teorema 1. Por qualquer ponto de uma reta, passa uma única perpendicular a esta reta.

Demostração: (Existência). Dada uma reta $m$ e um ponto $A$ sobre ela, as duas semirretas determinadas por $A$ formam um ângulo raso. Considere um dos semiplanos determinados por $m$. Segundo o axioma 7, entre todas as semirretas com origem em A, que dividem o semiplano fixado, existe uma cuja coordenada é 90 . Esta semirreta forma com as duas semirretas de origem em $A$ sobre a reta $m$, ângulos de $90^{\circ}$. Portanto ela é perpendicular a reta $m$.

(Unicidade). Suponha que existam duas retas $n$ e $n^{\prime}$ passando pelo ponto A e perpendicular a $m$. Fixe um semiplano determinado por $m$. As interseções das retas $n$ e $n^{\prime}$ com o semiplano fixado são semirretas que formam um ângulo $\alpha$, e outros dois ângulos $\beta$ e $\gamma$ com a reta $m$, conforme a figura abaixo. 


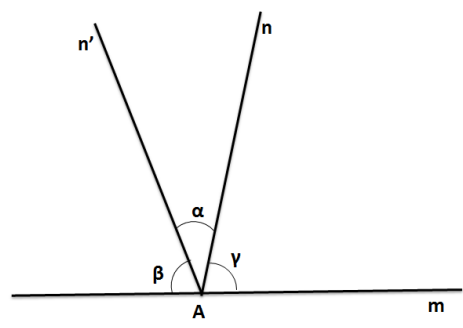

Como $n$ e $n^{\prime}$ são perpendiculares a $m, \beta=\gamma=90^{\circ}$. Porém, $\alpha+\beta+\gamma=180^{\circ}$. Logo $\alpha=0$ e assim concluímos que as retas $n$ e $n^{\prime}$ são coincidentes.

\subsection{Congruência}

Definição 7. Diremos que dois segmentos $A B$ e $C D$ são congruentes se $\overline{A B}=\overline{C D}$; diremos que dois ângulos $\hat{A}$ e $\hat{B}$ são congruentes se eles tem a mesma medida.

Para simplificar a notação, usaremos o símbolo "="para representar congruente. Assim, $A B=C D$ deve ser lido como $A B$ é congruente a $C D$ e $\hat{A}=\hat{B}$ deve ser lido como ângulo $\hat{A} e ́$ congruente ao ângulo $\hat{B}$.

Definição 8. Dois triângulos são congruentes se for possível estabelecer uma correspondência biunívoca entre seus vértices de modo que lados e ângulos correspondentes sejam congruentes.
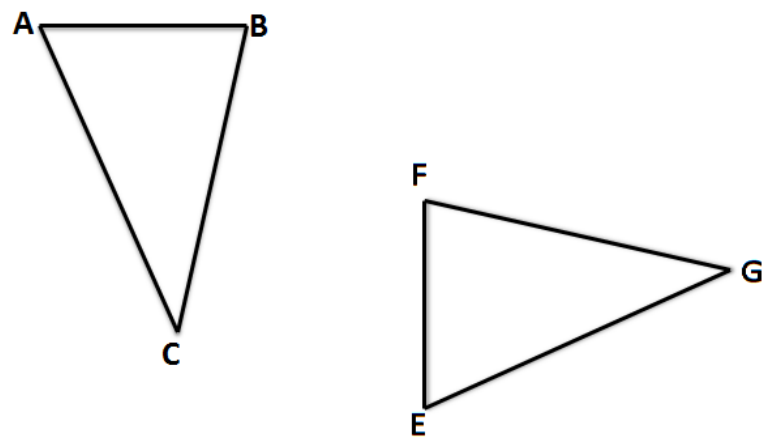

Figura 5 - Triângulos Congruentes

Se $A B C$ e $E F G$ são dois triângulos congruentes e se

$$
\begin{aligned}
& A \longleftrightarrow E \\
& B \longleftrightarrow F \\
& C \longleftrightarrow G
\end{aligned}
$$


é a correspondência que define a congruência, então valem: $A B=E F, B C=F G, A C=E G$, $\hat{A}=\hat{E}, \hat{B}=\hat{F}$ e $\hat{C}=\hat{G}$.

Escreveremos que $A B C=E F G$ para representar que os triângulos $A B C$ e $E F G$ são congruentes e que a correspondência entre os vétices é $A$ em $E, B$ em $F$ e $C$ em $G$.

Axioma 8. Dados dois triângulos $A B C$ e $E F G$, se $A B=E F, A C=E G$ e $\hat{A}=\hat{E}$ então $A B C=$ $E F G$.

Este axioma é conhecido como primeiro caso de congruência de triângulos.

Teorema 2. ( $2^{\circ}$ caso de congruência de triângulos) Dados dois triângulos $A B C$ e $E F G$ se $A B=E F, \hat{A}=\hat{E}$ e $\hat{B}=\hat{F}$, então $A B C=E F G$

Demonstração: Sejam $A B C$ e $E F G$ dois triângulos tais que $A B=E F, \hat{A}=\hat{E}$ e $\hat{B}=\hat{F}$. Seja $D$ um ponto na semirreta $S_{A C}$ tal que $A D=E G$.
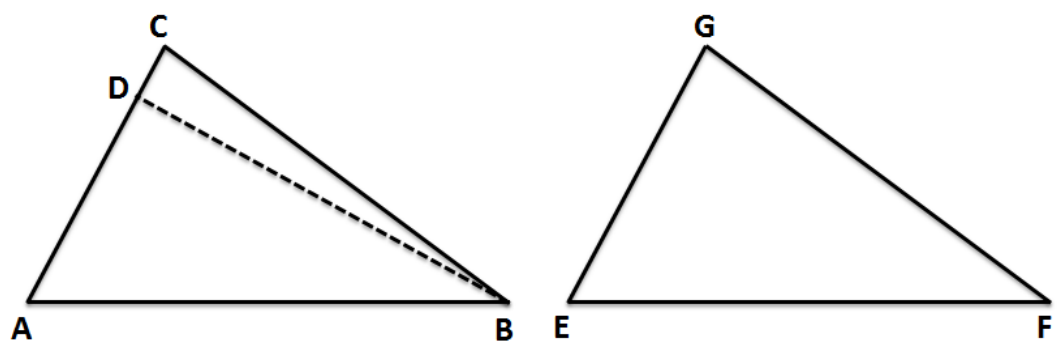

Consequentemente as semirretas $S_{B D}$ e $S_{B C}$ coincidem. E então pelo axioma 8 o ponto $D$ coincide com o ponto $C$, pois os triângulos $A B C$ e $A B D$ são congruentes. Como $A B D=E F G$, também pelo axioma 8 , então $A B C=E F G$.

Definição 9. Um triângulo é dito isósceles se tem dois lados congruentes. Estes lados congruentes são chamados de laterais e o outro lado é chamado de base.

Proposição 2. Em um triângulo isósceles os ângulos da base são congruentes.

Demonstração: Seja $A B C$ um triângulo isósceles em que $A B=A C$, queremos mostrar que $\hat{B}=\hat{C}$. Para isso, compare $A B C$ com ele mesmo, fazendo corresponder os vértices da seguinte maneira: $A \longleftrightarrow A ; B \longleftrightarrow C ; C \longleftrightarrow B$.

Como $A B=A C, A C=A B$ e $\hat{A}=\hat{A}$, então pelo axioma 8 , os triângulos são congruentes e $\hat{B}=\hat{C}$, como queriamos mostrar.

Definição 10. Seja $A B C$ um triângulo e seja $D$ um ponto da reta que contém $B$ e $C$. O segmento $A D$ chama-se mediana do triângulo $A B C$ relativo ao lado $B C$, se $D$ for o ponto médio de $B C$. O segmento $A D$ chama-se bissetriz do ângulo $\hat{A}$ se a semirreta $S_{A D}$ divide o ângulo $C \hat{A} B$ em dois ângulos iguais, ou seja, $C A D=B A D$. O segmento $A D$ chama-se altura do triângulo relativamente ao lado $B C$ se $A D$ for perpendicular a reta que contém $B$ e $C$. 
Proposição 3. Em um triângulo isósceles a mediana relativa a base é também bissetriz e altura.

Demonstração: Seja $A B C$ um triângulo isósceles cuja base é $A B$. Seja $C D$ sua mediana relativa à base. Devemos provar que $A \hat{C} D=B \hat{C} D$ e que $A \hat{D} C$ é um ângulo reto. Considere os triângulos $A D C$ e $B D C$. Como $A D=D B$, pois $C D$ é mediana e $A C=B C$, pois o triângulo é isósceles com base $A B$ e $C \hat{A} B=C \hat{B} A$, pela proposição anterior, logo o $A D C$ é congruente a $B D C$. Segue então que $A \hat{C} D=B \hat{C} D$ e $A \hat{D} C=B \hat{D} C$. A primeira igualdade nos diz que $C D$ é bissetriz e a segunda igualdade que $C D$ é altura, já que o ângulo $A \hat{D} B$ é raso.

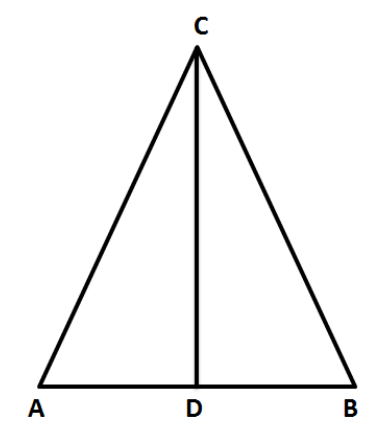

\subsection{Axioma das Paralelas}

Definição 11. Duas retas que não se interceptam são ditas paralelas.

Axioma 9. Por um ponto fora de uma reta $m$ pode-se traçar uma única reta paralela a $m$.

Proposição 4. Se a reta $m$ é paralela às retas $n_{1}$ e $n_{2}$, então $n_{1}$ e $n_{2}$ são paralelas ou coincidentes.

Demonstração: Suponha que $n_{1}$ e $n_{2}$ não coincidem e são paralelas a reta $m$. Se $n_{1}$ e $n_{2}$ não forem paralelas entre si, elas terão um ponto de interseção, digamos $P$. Mas então $n_{1}$ e $n_{2}$ seriam distintas paralelas à $m$ passando por $P$, o que contradiz o axioma 9 . Logo $n_{1}$ e $n_{2}$ são paralelas.

Corolário 1. Se uma reta corta uma de duas paralelas, então também corta a outra.

Demonstração: Sejam $n_{1}$ e $n_{2}$ retas paralelas. Se uma reta $m$ cortasse $n_{1}$ e não cortasse $n_{2}$, então $m$ e $n_{2}$ seriam paralelas. Assim $n_{2}$ seria paralela a $m$ e a $n_{1}$. Como $m$ e $n_{1}$ não são paralelas entre si, nem coincidentes, temos uma contradição com a proposição anterior. Logo $m$ corta também $n_{2}$.

A definição de retas paralelas não é tão simples quanto parece. Desde que retas são infinitas em comprimento, como poderiamos provar que duas retas não se interceptam? Por exemplo, as retas $m$ e $n$ da figura abaixo parecem ser paralelas. Como decidir se elas não se encontram em um lugar do plano muito distânte de $A$ e $B$ ? 


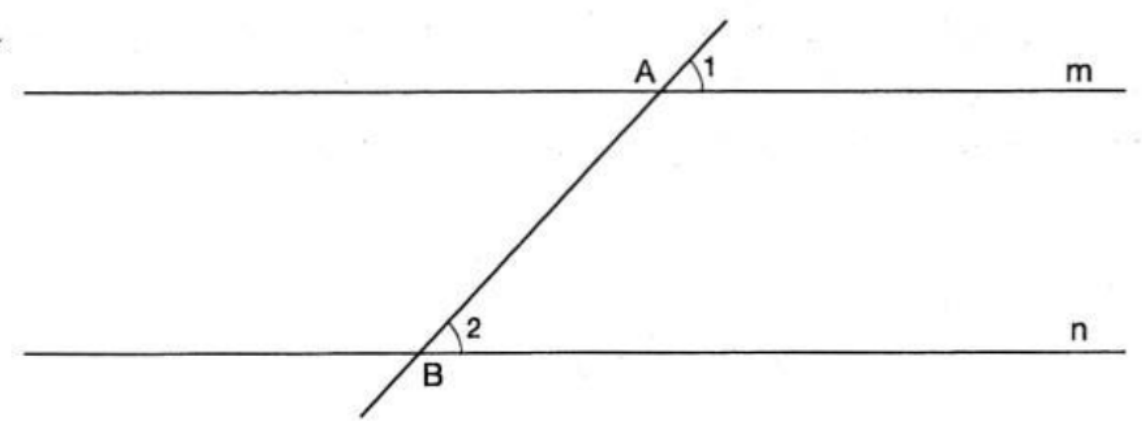

Figura 6 - Retas Paralelas

Uma maneira simples de responder a essa pergunta á através da comparação dos ângulos 1 e 2, indicados na figura, formados pelas duas paralelas e pela reta que passa por $A$ e $B$.

Proposição 5. Sejam $m, n$ retas, e os ângulos 1 e 2 como na figura acima. Se os ângulos 1 e 2 forem iguais, então as retas $m$ e $n$ são paralelas.
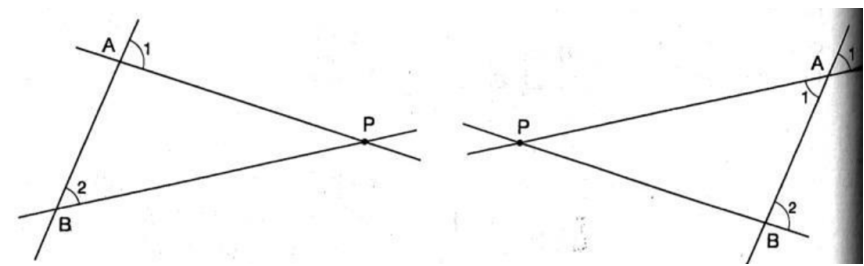

Demonstração: De fato, se $m$ interceptase $n$ em algum ponto $P$, seria formado o triângulo $A B P$. Neste triângulo, 1 é ângulo externo e 2 é um ângulo interno não-adjacente ao ângulo 1 , ou vice-versa. Assim, pelo teorema do ângulo externo ((BARBOSA, 1995) A medida de um ângulo externo de um triângulo é igual a soma das medidas dos ângulos internos não-adjacentes.) teríamos que os ângulos 1 e 2 seriam diferentes, o que contradiz nossa hipótese. Portanto $m$ e $n$ não se interceptam.

Quando duas retas são cortadas por uma transversal formam-se oito ângulos como indicado na figura abaixo. Quatro deles são correspondentes aos outros quatro, a saber:

$$
\begin{aligned}
& 1 \longleftrightarrow 2 \\
& 3 \longleftrightarrow 4 \\
& 5 \longleftrightarrow 6 \\
& 7 \longleftrightarrow 8
\end{aligned}
$$

Observação 1. Note que o ângulo 1 é igual ao 7 por serem opostos pelo vértice, assim como também 2 e 8, 3 e 5, 4 e 6. Como consequência, se o ângulo 1 for igual ao ângulo 2, então todos os outros pares de ângulos correspondentes serão iguais. Além disso, teremos que a soma dos 


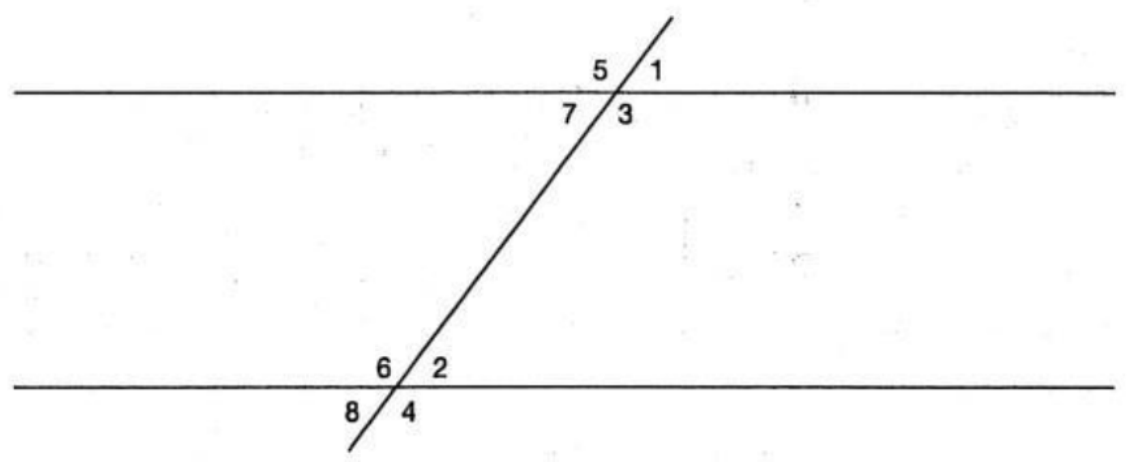

Figura 7 - Ângulos correspondentes em retas paralelas cortadas por uma transversal

ângulos 3 e 2 será $180^{\circ}$. Inversamente, se a soma dos ângulos 3 e 2 for $180^{\circ}$ então os ângulos 1 e 2 serão iguais. Estas observações permitem reescrever a Proposição 5 de duas maneiras distintas:

Corolário 2. Se ao cortarmos duas retas por uma transversal, e obtivermos a soma dos ângulos 3 e 2 igual a $180^{\circ}$, então as retas são paralelas.

Corolário 3. Se ao cortarmos duas retas por uma transversal, os ângulos correspondentes forem iguais, então as retas são paralelas.

O axioma 9 permite-nos mostrar que a inversa dessa proposição também é verdadeira.

Proposição 6. Se duas retas paralelas são cortadas por uma transversal, então os ângulos correspondentes são iguais.

Demonstração: Sejam $m$ e $m^{\prime}$ duas retas paralelas e seja $n$ uma reta que corta $m$ e $m^{\prime}$ nos pontos $A$ e $B$, respectivamente. Considere uma reta $m^{\prime \prime}$ passando pelo ponto $A$ e formando com a transversal quatro ângulos iguais aos ângulos correspondentes formados pelas retas $m^{\prime}$ com a mesma transversal. De acordo com a proposição anterior $m^{\prime}$ e $m^{\prime \prime}$ são paralelas. De acordo com a Proposição 4, $m$ e $m^{\prime \prime}$ são coincidentes. Portanto $m$ forma ângulos com a reta $n$ iguais aos correspondentes formados por $m^{\prime}$ com a reta $n$.

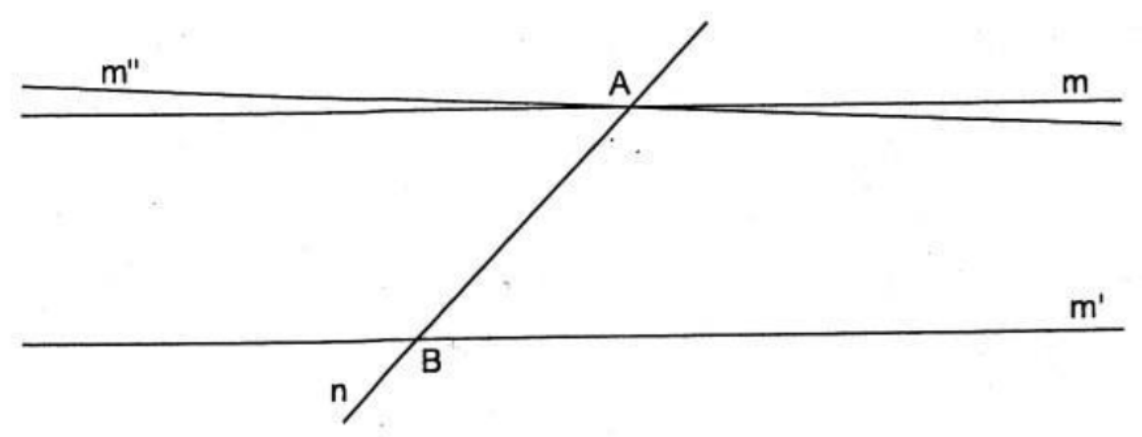

Corolário 4. Sejam duas retas paralelas cortadas por uma transversal conforme a figura abaixo. Então os ângulos 1, 7, 2 e 8 são iguais, assim como os ângulos 5, 3, 6 e 4. 


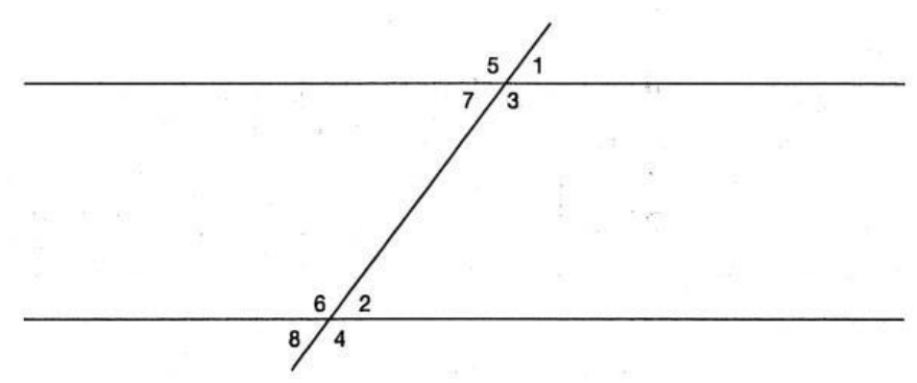

Demonstração: Pela Proposição 6, os ângulos 1 e 2 são iguais, mas como os ângulos 1 e 7 são iguais por serem opostos pelo vértice, assim como os ângulos 2 e 8, então os ângulos 1 , 7, 2 e 8 são iguais. Analogamente para os ângulos 5, 3, 6 e 4.

\subsection{Teorema de Pitágoras}

Definição 12. Um triângulo que possui um ângulo reto é chamado de triângulo retângulo. $\mathrm{O}$ lado oposto ao ângulo reto é chamado hipotenusa, e os outros dois lados são denominados catetos.

Teorema 3. (Pitágoras) Em todo triângulo retângulo o quadrado do comprimento da hipotenusa é igual a soma dos quadrados dos comprimentos dos catetos.

Demonstração: Para essa demonstração, assumiremos que um quadrado de lado com comprimento $l$ tem área igual a $l^{2}$ e que um triângulo retângulo de catetos com comprimentos $m$ e $n$ tem área igual a $\frac{m n}{2}$.

Seja um triângulo retângulo $A B C$ com ângulo reto em $A$ onde os catetos tem comprimentos $b$ e $c$ e a hipotenusa tem comprimento $a$, conforme a Figura 8 .

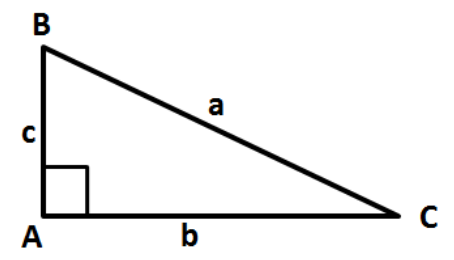

Figura 8 - Triângulo Reto

Note que com quatro triângulos congruentes ao triângulo $A B C$ e com um quadrado de lado $a$, podemos formar um quadrado de lado medindo $b+c$ conforme a figura abaixo: 


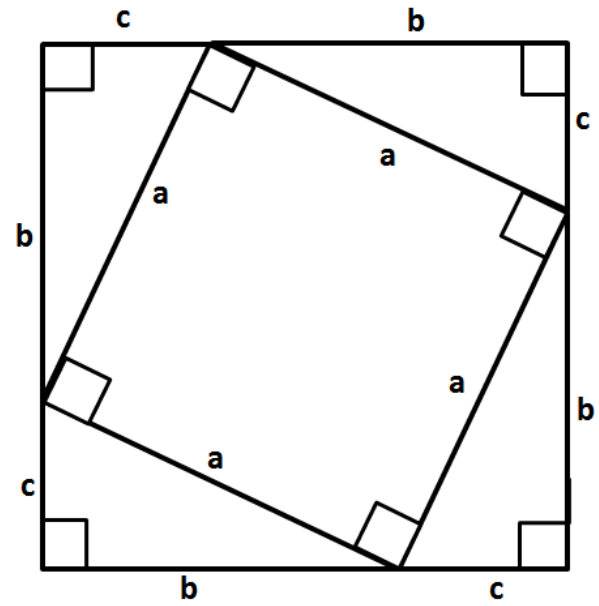

Sendo assim a área do quadrado com lado $b+c$ será igual a soma das áreas dos quatro triângulos congruentes e a do quadrado de lado $a$ formado. Logo,

$$
(b+c)^{2}=4 \frac{b c}{2}+a^{2},
$$

ou ainda

$$
b^{2}+2 b c+c^{2}=2 b c+a^{2},
$$

donde

$$
b^{2}+c^{2}=a^{2} .
$$

Portanto, o teorema está provado. 

CAPÍTULO
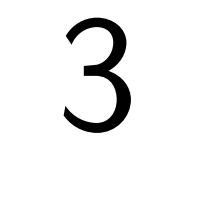

\section{CÔNICAS NO PLANO}

Neste capítulo, veremos as definições geométricas das cônicas, que serão usadas no Capítulo 4. Também com intuito de aproximar essa dissertação aos conteúdos estudados por um aluno do ensino médio, seguindo a referência de (DELGADO; FRENSEL; CRISSAFF, 2013), deduziremos as descrições algébricas mais simples das mesmas. Para isso, inicialmente faremos uma introdução as coordenadas cartesianas no plano.

\subsection{Coordenadas no plano}

Um sistema de eixos ortogonais num plano $\pi$ é um par de eixos, eixo $O X$ e eixo $O Y$, com unidade de medida de igual comprimento, que se intersectam perpendicularmente na origem comum $\mathrm{O}$. Faremos referência a esta configuração como sistema de eixos ortogonais $O X Y$ ou sistema $O X Y$.

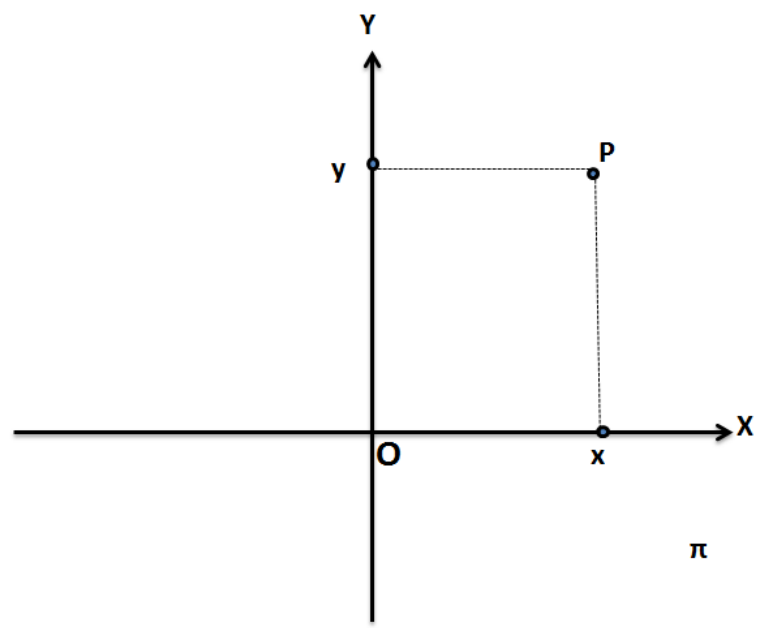

Figura 9 - Coordenadas $\mathrm{x}$ e y do ponto $\mathrm{P}$

A escolha de um sistema de eixos ortogonais permite estabelecer uma correspondên- 
cia biunívoca entre os pontos do plano $\pi$ e os pares ordenados de números reais do conjunto $\mathbb{R}^{2}=\{(x, y) ; x, y \in \mathbb{R}\}$.

De fato, ao ponto $P \in \pi$ fazemos corresponder o par ordenado (x,y) onde $x$ é a coordenada do pé da perpendicular ao eixo $O X$ que passa por $P$ e $y$ é a coordenada do pé da perpendicular ao eixo $O Y$ que passa por $P$.

Reciprocamente, ao par ordenadado $(x, y) \in \mathbb{R}^{2}$ associamos o ponto $P$ do plano $\pi$ dado pela intersecção da perpendicular ao eixo $O X$ que passa pelo ponto deste eixo de coordenada $x$ com a perpendicular ao eixo $O Y$ que passa pelo ponto deste eixo de coordenada $y$.

Os números $x, y \in \mathbb{R}$ do par ordenado $(x, y)$ associado ao ponto $P$ são as coordenadas cartesianas do ponto $P$ : $x$ é a abscissa ou primeira coordenada de $P$ e $y$ é a ordenada ou segunda ordenada de $P$.

Notação: Se $P \in \pi$ corresponde a $(x, y) \in \mathbb{R}^{2}$, escrevemos $P=(x, y)$.

\subsubsection{Distância entre pontos no plano}

Sejam $P=(a, b)$ e $Q=(c, d)$ pontos do plano $\pi$ dados por suas coordenadas em relação a um sistema de eixos ortogonais $O X Y$.

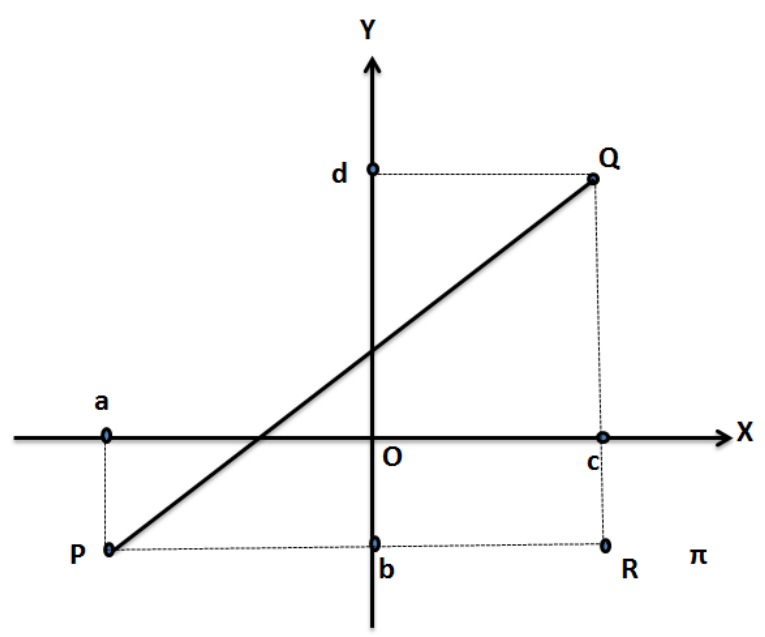

Figura 10 - Distância entre pontos do plano

A distância de $P$ a $Q$, que denotamos por $\overline{P Q}$ ou $d(P, Q)$, é a medida da hipotenusa $P Q$ do triângulo retângulo $P Q R$ de catetos $P R$ e $Q R$, onde $R=(c, b)$. Como $\overline{P R}=|a-c|$ e $\overline{Q R}=|b-d|$, então pelo Teorema de Pitágoras obtemos:

$$
d(P, Q)=\overline{P Q}=\sqrt{\overline{P R}^{2}+\overline{Q R}^{2}}=\sqrt{(a-c)^{2}+(b-d)^{2}} .
$$




\subsection{Definição e tratamento algébrico das cônicas}

Especula-se que o estudo das cônicas tenha começado com os gregos, incentivado pelo anseio de resolver problemas como a duplicação do cubo, a trisseção de um ângulo e a quadratura do círculo. Pelo que se sabe o primeiro a estudá-las foi o matemático Menaecmus (380 - 320 a.C. aproximadamente), a descoberta das curvas cônicas ou seções cônicas. Mais tarde, o astrônomo e matemático grego Apolônio de Perga (262 - 190 a.C.) aprimorou os resultados conhecidos até então sobre o assunto na sua obra Seções Cônicas, que mostrou que as cônicas podem ser obtidas a partir de um mesmo cone de base circular, bastando para tal fazer variar a inclinação do plano de interseção.

Pierre de Fermat através das propriedades que definem as seções cônicas, obteve suas equações. Seus estudos e análises deram lugar a sete equações que obteve como formas irredutíveis a partir da equação geral do segundo grau com duas variáveis que, escrita na linguagem atual, é:

$$
A x^{2}+B x y+C y^{2}+D x+E y+F=0, \operatorname{com} A, B, C, D, E, F \in \mathbb{R} .
$$

Nosso objetivo agora é estudar a equação geral acima nos casos em que $A \neq 0$ ou $B \neq 0$ ou $C \neq 0$. Para isso definiremos, geometricamente, uma parábola, uma elipse e uma hipérbole. $\mathrm{E}$ através dessas definições encontraremos suas equações reduzidas.

\subsubsection{Parábola}

Definição 13. Sejam $L$ uma reta e $F$ um ponto no plano $\pi$ não pertencente a $L$. A parábola $\Sigma$ de foco $F$ e diretriz $L$ é o conjunto de pontos do plano cuja distância a $F$ é igual à sua distância a $L$ :

$$
\Sigma=\{P \in \pi ; d(P, F)=d(P, L)\} .
$$

\section{Terminologia}

- A reta focal $l$ da parábola $\Sigma$ é a reta que contém o foco e é perpendicular à diretriz.

- O ponto $V$ da parábola $\Sigma$ que pertence à reta focal é o vértice de $\Sigma$. Se $A$ é o ponto onde $L$ intersecta $l$, então $V$ é o ponto médio do segmento $A F$.

Vamos obter a forma canônica da parábola com vértice na origem e reta focal coincidente com o eixo $O Y$.

Caso I. O foco está acima da diretriz $L$

Neste caso, $F=(0, p)$ e $L: y=-p$, onde $2 p=d(F, L)$. Logo,

$$
\begin{gathered}
P=(x, y) \in \Sigma \Leftrightarrow d(P, F)=d(P, L) \Leftrightarrow \sqrt{x^{2}+(y-p)^{2}}=|y+p| \\
\Leftrightarrow x^{2}+(y-p)^{2}=(y+p)^{2} \Leftrightarrow x^{2}+y^{2}-2 y p+p^{2}=y^{2}+2 y p+p^{2} .
\end{gathered}
$$


Logo

$$
x^{2}=4 p y
$$

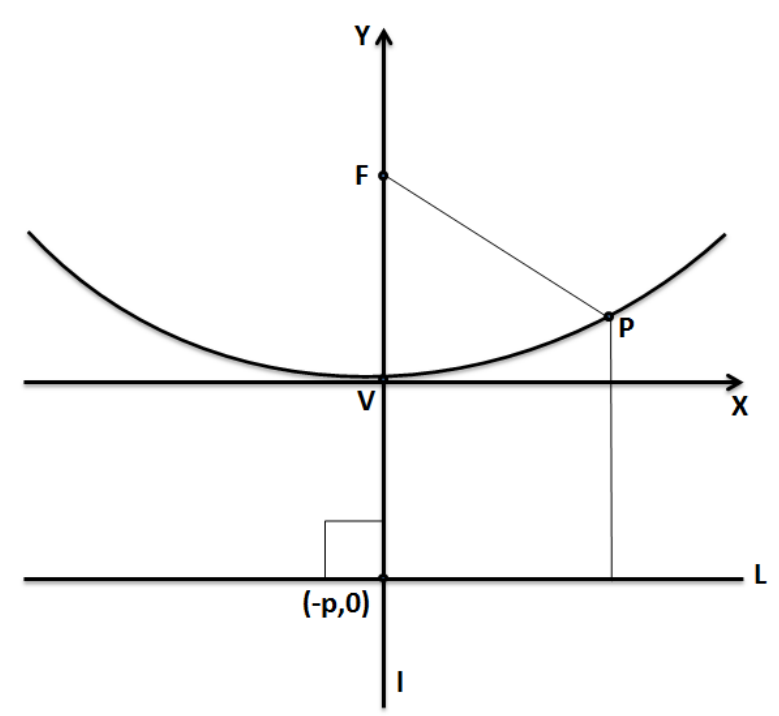

Figura $11-$ Parábola $x^{2}=4 p y$

Caso II. O foco está abaixo da diretriz $L$

Neste caso, $F=(0,-p)$ e $L: y=p$, onde $2 p=d(F, L)$. Logo,

$$
\begin{gathered}
P=(x, y) \in \Sigma \Leftrightarrow \sqrt{x^{2}+(y+p)^{2}}=|y-p| \\
\Leftrightarrow x^{2}+(y+p)^{2}=(y-p)^{2} \Leftrightarrow x^{2}+y^{2}+2 y p+p^{2}=y^{2}-2 y p+p^{2} .
\end{gathered}
$$

Portanto

$$
x^{2}=-4 p y
$$

Faremos também um caso em que o vértice não é a origem, para que encontremos a forma mais ampla das parábolas, formas que são vistas no ensino médio.

Caso III. Parábola com vértice $V=\left(x_{0}, y_{0}\right)$ e reta focal paralela ao eixo $O Y$

Considerando o sistema de eixos ortogonais $\overline{O X Y}$, com origem $\bar{O}=V=\left(x_{0}, y_{0}\right)$ e eixos $\overline{O X}$ e $\overline{O Y}$ que tem a mesma direção e sentido dos eixos $O X$ e $O Y$, respectivamente, podemos obter a equação e os elementos da parábola com vértice $V=\left(x_{0}, y_{0}\right)$ e reta focal paralela ao eixo $O Y$. Veremos o caso em que F está acima da diretriz $L$. Sabemos que no sistema de coordenadas $\overline{O X Y}$ a equação da parábola é $\bar{x}^{2}=4 p \bar{y}$; o foco é $\bar{F}=(0, p)$; o vértice é $\bar{V}=(0,0)$; a diretriz é $L: \bar{y}=-p$ e a reta focal é $\bar{l}: \bar{x}=0$. Como $x=\bar{x}+x_{0}$ e $y=\bar{y}+y_{0}$, no sistema $O X Y$, o foco é $F=\left(x_{0}, y_{0}+p\right)$; a diretriz é $L: y=y_{0}-p$; a reta focal é $l: x=x_{0}$ e a equação da parábola será:

$$
\left(x-x_{0}\right)^{2}=4 p\left(y-y_{0}\right)
$$


Desenvolvendo essa equação e isolando "y"temos:

$$
y=\frac{1}{4 p} x^{2}-\frac{x_{0}}{2 p} x+\frac{\left(x_{0}^{2}+4 p y_{0}\right)}{4 p} .
$$

Fazendo

$$
a=\frac{1}{4 p}, \quad b=-\frac{x_{0}}{2 p}, \quad e \quad c=\frac{\left(x_{0}^{2}+4 p y_{0}\right)}{4 p},
$$

a equação da parábola se reduz a seguinte forma:

$$
y=a x^{2}+b x+c .
$$

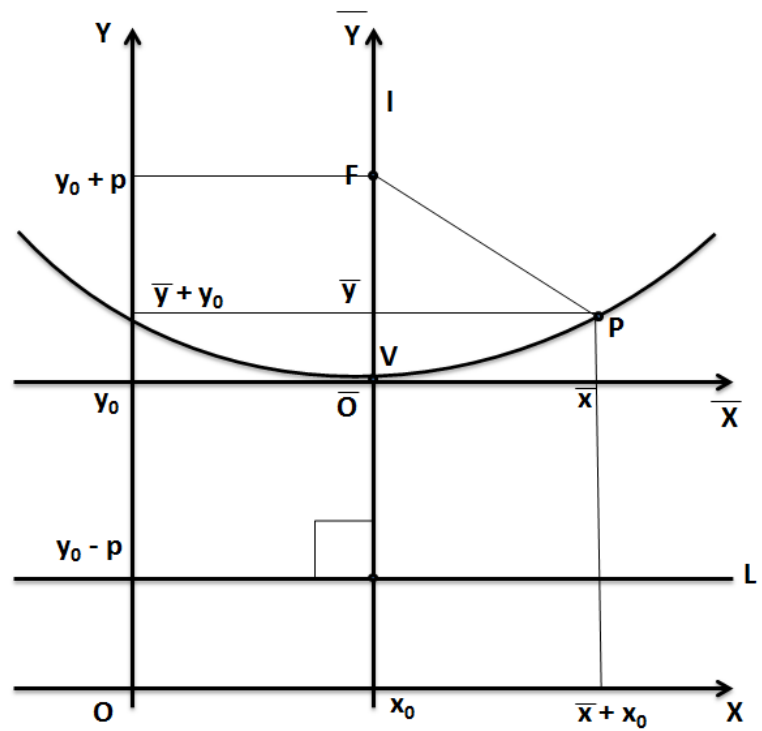

Figura 12 - Parábola $y=a x^{2}+b x+c$

Observação 2. Dada a equação da parábola (3.6), um problema de interesse é determinar seu vértice em termos dos parâmetros $a, b, c$. De fato, usando (3.5), obtem-se que o vértice $V=\left(x_{0}, y_{0}\right)$ pode ser escrito como

$$
V=\left(\frac{-b}{2 a}, \frac{-\Delta}{4 a}\right) \text {, em que } \Delta=b^{2}-4 a c .
$$

Exemplo 1. Determine a equação da parábola de vértice $V=(3,4)$ e foco $F=(3,6)$. Encontre também a equação de sua diretriz.

Solução: Como $V=(3,4)$ e $F=(3,6), l: x=3$ é a reta focal e $F$ está acima de $V$, ou seja, acima da diretriz $L$. Logo, a equação da parábola é da forma:

$$
(x-3)^{2}=4 p(y-4) .
$$

Sendo $p=d(V, F)=2$, temos que $L: y=2$ é a diretriz e a equação da parábola é:

$$
(x-3)^{2}=8(y-4)
$$




\subsubsection{Elipse}

Definição 14. Uma elipse $E$ de focos $F_{1}$ e $F_{2}$ é o conjunto de todos os pontos $P$ do plano $\pi$ cuja soma das distâncias a $F_{1}$ e $F_{2}$ é igual a uma constante $2 a>0$, maior do que a distância entre os focos $2 c \geq 0$ :

$$
E=\left\{P \in \pi ; d\left(P, F_{1}\right)+d\left(P, F_{2}\right)=2 a\right\}
$$

\section{Terminologia}

- Os pontos $F_{1}$ e $F_{2}$ são os focos da elipse.

- A reta $l$ que contém os focos é a reta focal.

- A interseção da elipse com a reta focal $l$ consiste exatamente em dois pontos, $A_{1}$ e $A_{2}$, chamados vértices da elipse sobre a reta focal.

- O segmento $A_{1} A_{2}$ de comprimento $2 a$ é o eixo focal da elipse.

- O centro $C$ da elipse é o ponto médio do eixo focal $A_{1} A_{2}$.

- A reta não focal é a reta $l^{\prime}$ perpendicular a $l$ que passa pelo centro $C$.

- A elipse intersecta a reta não focal $l^{\prime}$ em exatamente dois pontos $B_{1}$ e $B_{2}$. De modo que, $B_{1} B_{2}$ tem comprimento $2 b$, onde $b^{2}=a^{2}-c^{2}$.

Vamos obter a equação reduzida da elipse $E$ com centro na rigem e reta focal coincidente com o eixo $O X$.

Neste caso,os focos e vértices de $E$ são: $F_{1}=(-c, 0), F_{2}=(c, 0), A_{1}=(-a, 0), A_{2}=$ $(a, 0), B_{1}=(0,-b)$ e $B_{2}=(0, b)$, onde $0<c<a$ e $b=\sqrt{a^{2}-c^{2}}$. Logo,

$$
\begin{gathered}
P=(x, y) \in E \Leftrightarrow d\left(P, F_{1}\right)+d\left(P, F_{2}\right)=2 a \\
\Leftrightarrow \sqrt{(x+c)^{2}+y^{2}}+\sqrt{(x-c)^{2}+y^{2}}=2 a \\
\Leftrightarrow \sqrt{(x+c)^{2}+y^{2}}=2 a-\sqrt{(x-c)^{2}+y^{2}} \\
\Leftrightarrow x^{2}+2 x c+c^{2}+y^{2}=4 a^{2}-4 a \sqrt{(x-c)^{2}+y^{2}}+x^{2}-2 x c+c^{2}+y^{2} \\
\Leftrightarrow a^{2}-c x=a \sqrt{(x-c)^{2}+y^{2}}
\end{gathered}
$$




$$
\begin{gathered}
\Leftrightarrow\left(a^{2}-c x\right)^{2}=a^{2}\left((x-c)^{2}+y^{2}\right. \\
\Leftrightarrow\left(a^{2}-c^{2}\right) x^{2}+a^{2} y^{2}=a^{4}-a^{2} c^{2}=a^{2}\left(a^{2}-c^{2}\right) \\
\Leftrightarrow b^{2} x^{2}+a^{2} y^{2}=a^{2} b^{2} \\
\Leftrightarrow \frac{x^{2}}{a^{2}}+\frac{y^{2}}{b^{2}}=1 .
\end{gathered}
$$

A equação acima é a forma canônica da elipse de centro na origem e reta focal coincidente com o eixo $O X$.

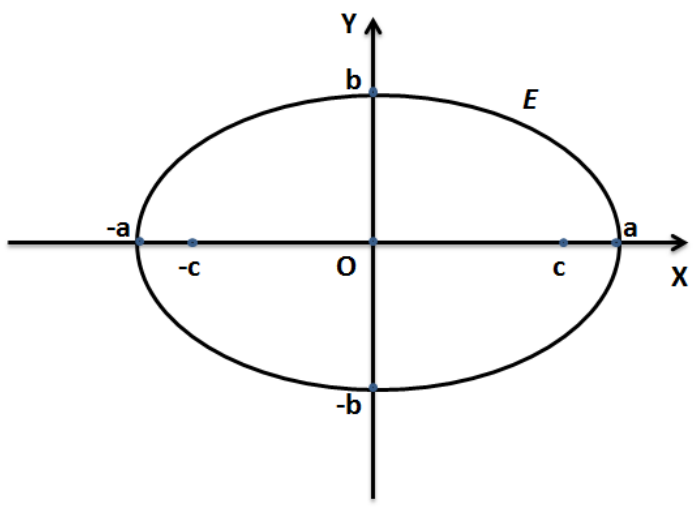

Figura 13 - Elipse

Exemplo 2. Os pontos $(4,0)$ e $(-4,0)$ são vértices de uma elipse cujos focos são os pontos $(3,0)$ e $(-3,0)$. Determine a equação da elipse.

Solução: Como $F_{1}=(-3,0)$ e $F_{2}=(3,0)$, a reta focal é o eixo $O X$ e $A_{1}=(-4,0), A_{2}=(4,0)$ são os vértices sobre a reta focal $l$. Então, $C=\frac{F_{1}+F_{2}}{2}=\frac{A_{1}+A_{2}}{2}=(0,0)$ é o centro da elipse, $a=$ $d\left(C, A_{1}\right)=d\left(C, A_{2}\right)=4, c=d\left(C, F_{1}\right)=d\left(C, F_{2}\right)=3$ e $b=\sqrt{a^{2}-c^{2}}=\sqrt{4^{2}-3^{2}}=\sqrt{16-9}=$ $\sqrt{7}$. Logo a equação da elipse é

$$
\frac{x^{2}}{16}+\frac{y^{2}}{7}=1
$$

\subsubsection{Hipérbole}

Definição 15. Uma hipérbole $H$ de focos $F_{1}$ e $F_{2}$ é o conjunto de todos os pontos $P$ do plano $\pi$ para os quais o módulo da diferença de suas distâncias a $F_{1}$ e $F_{2}$ é igual a uma constante $2 a>0$, com $0<a<c$, em que $d\left(F_{1}, F_{2}\right)=2 c$, isto é,

$$
H=\left\{P \in \pi ;\left|d\left(P, F_{1}\right)-d\left(P, F_{2}\right)\right|=2 a\right\} .
$$




\section{Terminologia:}

- Os pontos $F_{1}$ e $F_{2}$ são os focos da hipérbole.

- A reta $l$ que contém os focos é a reta focal.

- A interseção da hipérbole com a reta focal $l$ consiste exatamente em dois pontos, $A_{1}$ e $A_{2}$, chamados vértices da hipérbole.

- O segmento $A_{1} A_{2}$ de comprimento $2 a$ é o eixo focal da hipérbole.

- O centro $C$ da hipérbole é o ponto médio do eixo focal $A_{1} A_{2}$. O centro $C$ é também o ponto médio do segmento $F_{1} F_{2}$ delimitado pelos focos, ou seja, $d\left(C, F_{1}\right)=d\left(C, F_{2}\right)=c \mathrm{e}$ $d\left(C, A_{1}\right)=d\left(C, A_{2}\right)=a$.

- A reta não focal é a reta $l^{\prime}$ perpendicular a $l$ que passa pelo centro $C$.

- O segmento $B_{1} B_{2}$, perpendicular ao eixo focal que tem ponto médio $C$ e comprimento $2 b$, onde $b^{2}=c^{2}-a^{2}$, é denominado eixo não focal da hipérbole, e $B_{1}$ e $B_{2}$ são os vértices imaginários da hipérbole.

Vamos obter a equação reduzida da hipérbole $H$ com centro na origem e reta focal coincidente com o eixo $O X$.

Neste caso, $F_{1}=(-c, 0), F_{2}=(c, 0), A_{1}=(-a, 0), A_{2}=(a, 0), B_{1}=(0,-b)$ e $B_{2}=$ $(0, b)$. Logo,

$$
\begin{gathered}
P=(x, y) \in H \Leftrightarrow\left|d\left(P, F_{1}\right)-d\left(P, F_{2}\right)\right|=2 a \\
\Leftrightarrow\left\{\begin{array}{c}
d\left(P, F_{1}\right)-d\left(P, F_{2}\right)=2 a(\text { ramodireitode } H) \\
\text { ou } \\
d\left(P, F_{1}\right)-d\left(P, F_{2}\right)=-2 a(\text { ramoesquerdode } H)
\end{array}\right. \\
\Leftrightarrow\left\{\begin{array}{c}
\sqrt{(x+c)^{2}+y^{2}}-\sqrt{(x-c)^{2}+y^{2}}=2 a(\text { ramodireitode } H) \\
\text { ou } \\
\sqrt{(x+c)^{2}+y^{2}}-\sqrt{(x-c)^{2}+y^{2}}=-2 a .(\text { ramoesquerdode } H)
\end{array}\right.
\end{gathered}
$$

Continuando o desenvolvimento de maneira análoga ao caso da elipse, e lembrando que $b^{2}=c^{2}-a^{2}$, chegamos à conclusão que

$$
\begin{aligned}
P=(x, y) \in H & \Leftrightarrow\left(c^{2}-a^{2}\right) x^{2}-a^{2} y^{2}=a^{2}\left(c^{2}-a^{2}\right) \\
\Leftrightarrow & b^{2} x^{2}-a^{2} y^{2}=a^{2} b^{2} \\
& \Leftrightarrow \frac{x^{2}}{a^{2}}-\frac{y^{2}}{b^{2}}=1 .
\end{aligned}
$$


Esta última equação é a forma canônica da equação da hipérbole de centro na origem e reta focal coincidente com o eixo $O X$.

As assíntotas de $H$ são as retas que passam pela origem (centro) e têm inclinação $\pm \frac{b}{a}$ em relação ao eixo $O X$ (reta focal), suas equações são $y= \pm \frac{b}{a} x$.

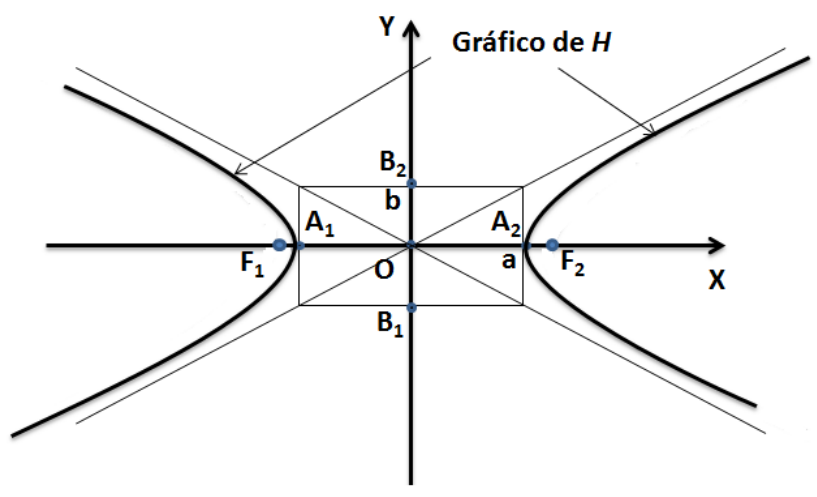

Figura 14 - Hipérbole

Exemplo 3. Os vértices de uma hipérbole são os pontos $(0,3)$ e $(0,-3)$ e um dos seus focos é o ponto $(0,5)$. Determine a equação da hipérbole, o comprimento do seu eixo focal e suas assíntotas.

Solução: A hipérbole tem centro $C=\frac{(0,3)+(0,-3)}{2}=(0,0)$, reta focal $=$ eixo $O Y, c=d((0,0),(0,5))=$ $5, a=d((0,0),(0,3))=5$ e $b^{2}=c^{2}-a^{2}=25-9=16$. Logo a equação da hipérbole é $\frac{y^{2}}{9}-\frac{x^{2}}{16}=1 . x= \pm \frac{4}{3} y$ são as suas assíntotas e $2 a=6$ é o comprimento do seu eixo focal. 



\section{ESPELHOS CÔNICOS E APLICAÇÕES}

Neste capítulo, seguindo as referências (WAGNER, 1997) (ÁVILA, 1997) (VALLADARES, 1998) demonstraremos as principais propriedades dos espelhos cônicos, espelhos em forma de parábola, elipse e hipérbole. Para a realização das demonstrações descreveremos alguns princípios básicos da óptica tendo como referência (COURROL; PRETO, 2016). Essas propriedades darão aos espelhos utilidades físicas que usamos em diversas situações. Mostraremos algumas delas nesse capítulo também.

\section{1 Óptica Geométrica e Reflexão}

A Óptica Geométrica considera a luz formada por raios de luz, como diz Ramalho: "raios de luz são linhas orientadas que representam graficamente a direção e o sentido de propagação da luz"(Ramalho et al.1990). Mais tarde percebeu-se que a luz se comporta ora por raios e ora por ondas.

A óptica geométrica se apóia em três princípios:

I) Princípio da propagação retilínia da luz: Nos meios homogêneos e transparentes, a luz se propaga em linha reta.

II) Princípio da reversibilidade dos raios de luz: A trajetória seguida pela luz independente do sentido do percurso.

III) Princípio da independência dos raios de luz: quando raios se cruzam, cada um deles segue seu trajeto como se o outro não existisse.

Consideremos a reflexão de um raio de luz numa superfície $S$, sendo $R I$ o raio incidente no ponto $I$ da superfície $S$, o qual forma com a normal à superfície $(N)$ o ângulo de incidência $i$. $\mathrm{O}$ raio refletido $R R$ após a reflexão, forma com a normal $N$ o ângulo de reflexão $r$. 

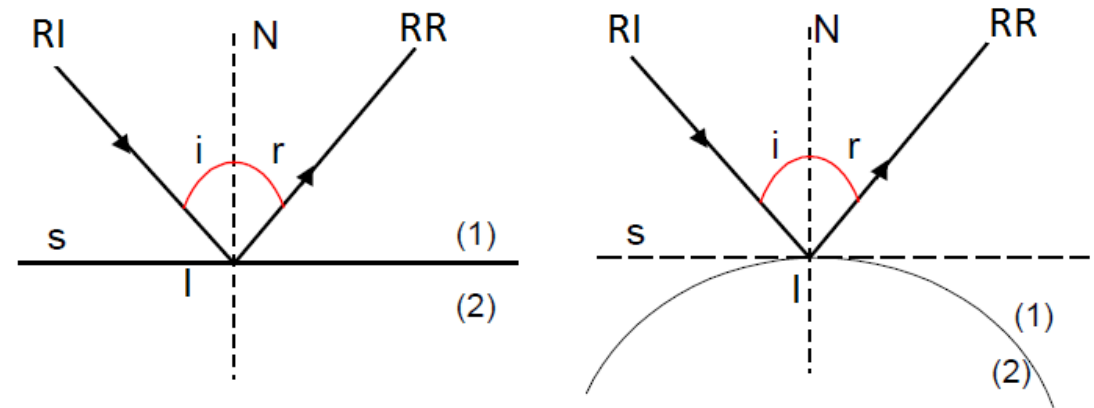

Figura 15 - Reflexão da luz em superfície plana e esférica.

Leis da Reflexão:

I) O raio refletido, a normal e o raio incidente estão situados num mesmo plano.

II) O ângulo de incidência é igual ao ângulo de reflexão, ou seja, i=r.

\subsection{Espelho Parabólico}

Nesta secção vamos apresentar um resultado central envolvendo espelhos parabólicos (Teorema 4) e apresentar algumas aplicações que decorrem deste resultado.

Teorema 4. Um raio incidente paralelo ao eixo da parábola, reflete, convergindo para o foco.

Demonstração: Seja $P$ um ponto qualquer da parábola que tem foco $F$ e reta diretriz $L$. Seja também o ponto $D \in L, D$ a projeção ortogonal de $P$ sobre $L$. Mostremos inicialmente que a reta $t$, reta bissetriz do ângulo $F P D$, é a reta tangente à parábola ${ }^{1} \mathrm{em} P$.

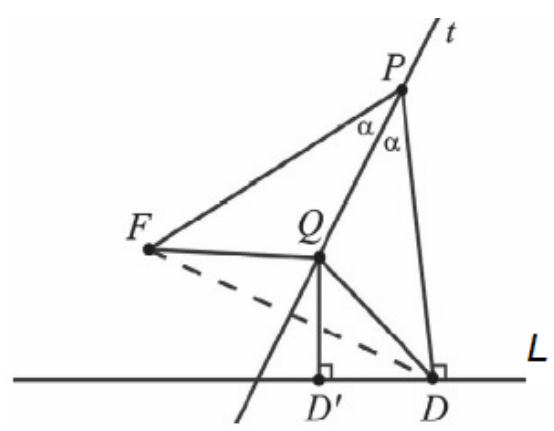

Figura 16 - Reta t, reta tangente em P

Como $d(P, F)=d(P, D)$, pois $P$ é um ponto da parábola, o triângulo $P F D$ é isósceles. E como $t$ é a bissetriz de $F P D, t$ também é altura, mediana e mediatriz do lado $F D$. Seja $Q$ um ponto de $t, Q \neq P$, seja $D^{\prime}$ projeção ortogonal de $Q$ sobre a reta $L$, desse modo notamos que $d(Q, F)=d(Q, D)>d\left(Q, D^{\prime}\right)$.

1 Uma reta $r$ é tangente a uma parábola $P$, se $r$ não é paralela ao eixo da parábola e $r \cap P$ contém apenas um ponto, $T$, chamado ponto de tangência. 
Com isso, nota-se que $Q$ não pertence a parábola já que a $d(Q, F) \neq d(Q, L)$. Logo $P$ é o único ponto de $t$ que pertence a parábola, logo $t$ é a reta tangente à parábola em $P$.

Agora, usando o fato de que a reta tangente em $P$ é a bissetriz do ângulo $F P D$ mostraremos que o raio paralelo ao eixo da parábola converge para o foco.

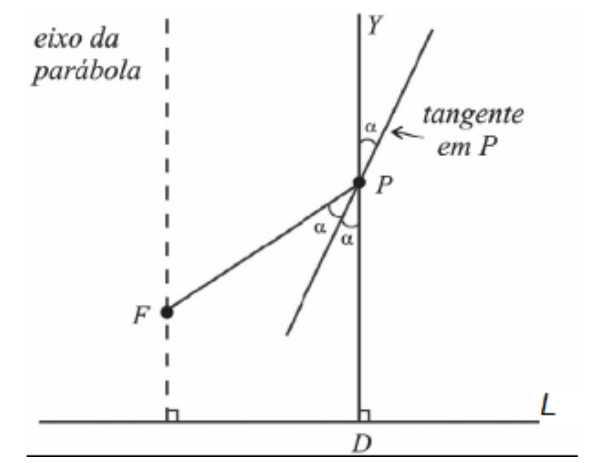

Figura 17 - Lei da reflexão na parábola.

Observando a figura acima, vemos que, prolongando o segmento $P D$, formamos a semirreta $P Y$. Seja $\alpha$ o ângulo agudo formado entre a semirreta $P Y$ e a reta $t$. Como o ângulo oposto pelo vértice também é $\alpha$, segue que as semirretas $P Y$ e $P F$ fazem ângulos congruentes com a reta tangente. Segundo a lei da reflexão que diz "que o ângulo de incidência é igual ao de reflexão", todo raio recebido na direção do eixo da parábola, converge para o foco após a reflexão.

No que segue vamos apresentar aplicações do Teorema 4, com a referência de (MACHADO, 2007)

\subsubsection{Farol Parabólico}

Ao acendermos os faróis do carro, os raios de luz, provenientes da lâmpada, incidem num espelho parabólico e são refletidos paralelamente ao eixo de simetria, o que faz com que a eficiência do farol aumente consideravelmente, como esquematiza a figura a seguir:

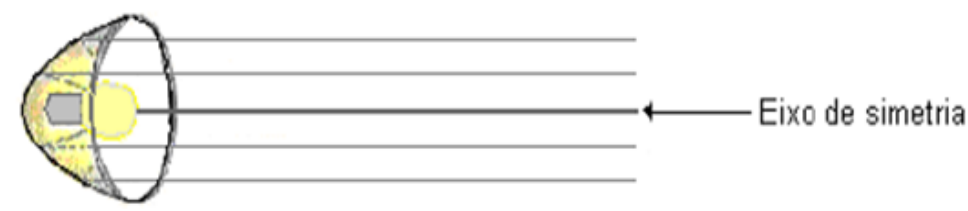

Figura 18 - Farol Parabólico

\subsubsection{Forno Solar}

Em uma região da França onde a incidência de luz do Sol é intensa, foi construído um grande espelho côncavo, que é usado como "forno solar". Como a distância do Sol à Terra 
é de cerca de 150 milhões de quilômetros, quando o feixe de luz solar nos atinge seus raios já estão praticamente paralelos. Portanto, ao se refletirem no espelho, os raios desse feixe convergem para seu foco, onde haverá uma grande concentração de energia, tanto luminosa quanto térmica. Assim, no foco do espelho há uma elevação de temperatura e, nesse ponto, é colocado o dispositivo que irá utilizar a energia concentrada. Se a distância focal do espelho for $10 \mathrm{~m}$, esse dispositivo deverá ser colocado a $10 \mathrm{~m}$ do vértice do espelho, ficando assim, exatamente sobre o foco.

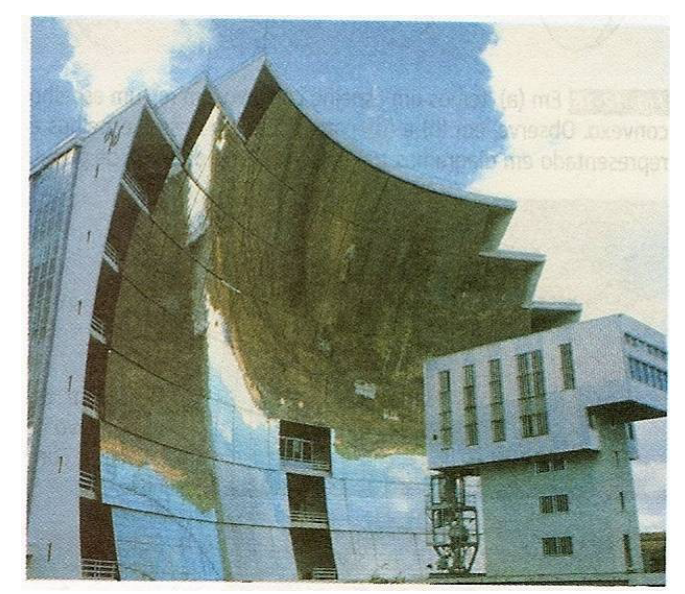

Figura 19 - Forno Solar

\subsubsection{Antena Parabólica}

As antenas parabólicas, apesar de não refletirem luz, são espelhos. Elas são construídas para refletir ondas de radiofreqüências, que tem comprimento de onda muito maior do que o da luz, com valores que variam de algumas centenas de metros até o mínimo de cerca de $0,3 \mathrm{~m}$. Para esses comprimentos de onda, quase todas as superfícies são espelhos, mesmo que sejam cheias de buracos, como uma tela de arame. Se as ondas eletromagnéticas emitidas por um satélite, atingirem a antena parabólica, ocorrerá a reflexão desses raios a um ponto chamado foco da parábola, onde está um aparelho receptor que converterá as ondas eletromagnéticas em um sinal elétrico que a TV transformará em imagens, que serão os programas que passam e as pessoas assistem diariamente.

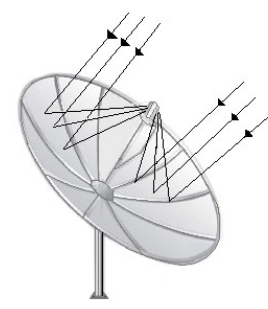

Figura 20 - Antena Parabólica 


\subsection{Espelho Elíptico}

Nesta secção vamos apresentar um resultado central envolvendo espelhos elípticos (Teorema 5) e apresentar algumas aplicações que decorrem deste resultado.

Teorema 5. Um raio incidente que passa por um dos focos de uma elipse, reflete passando pelo outro foco.

Demonstração: Seja uma elipse $E$ com focos $F_{1}$ e $F_{2}$ e seja um ponto $X \in E$. Nesse caso, basta mostrar que a reta $r$, tangente a $E$ em $X^{2}$, forma ângulos iguais com $F_{1} X$ e $F_{2} X$, pois segundo a lei de reflexão, o ângulo de incidência é igual ao ângulo de reflexão.

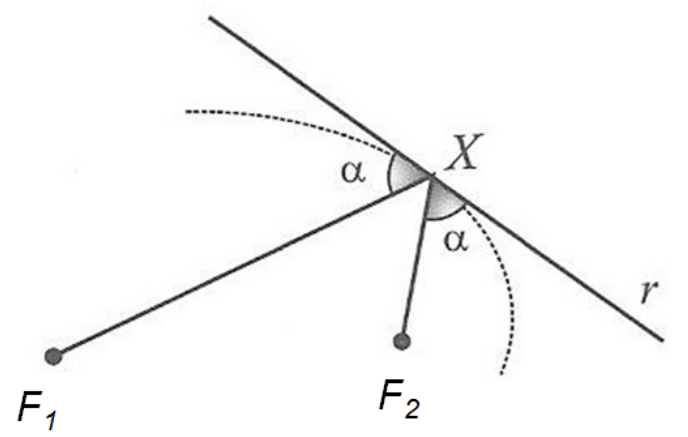

Figura 21 - Lei da reflexão na elipse.

Lembremos que, tal como na circunferência, uma reta $r$ é tangente a uma elipse $E$ no ponto $X$ se, e somente se, $r \cap E=X$. Caracterizando a elipse $E$ como o lugar geométrico dos pontos $X$ que satisfazem a propriedade métrica,

$$
d\left(X, F_{1}\right)+d\left(X, F_{2}\right)=k(\text { constante }) .
$$

Logo, uma reta $r$ será tangente à elipse $E$ em um ponto $X$ se e se somente se intersectar $E$ em $X$ e qualquer que seja o ponto $A$ em $r, A \neq X$, se tenha:

$$
d\left(A, F_{1}\right)+d\left(A, F_{2}\right) \neq d\left(X, F_{1}\right)+d\left(X, F_{2}\right) .
$$

Seja agora, um ponto $X$ na elipse $E$ e tomemos uma reta $r$ passando por $X$ de tal forma que o ângulo entre $F_{1} X$ e $r$ seja igual ao ângulo entre $F_{2} X$ e $r$. Se mostrarmos que $r$ é tangente a $E$ em $X$, teremos mostrado a propriedade, devido à unicidade da tangente à elipse por um de seus pontos.

Como $X$ é um ponto de $E, \operatorname{logo} d\left(X, F_{1}\right)+d\left(X, F_{2}\right)=k$. Tomemos sobre $r$ um ponto $A \neq X$ e consideremos o ponto $F_{1}^{\prime}$, simétrico de $F_{1}$ em relação a $r$, ou seja, $F_{1}^{\prime}$ pertence a reta que passa por $F_{1}$ e é ortogonal a $r$, e $d\left(F_{1}, r\right)=d\left(F_{1}^{\prime}, r\right)$. Seja também 0 o ponto de intersecção entre $F_{1} F_{1}^{\prime}$ e $r$, conforme a figura abaixo:

2 Uma reta $r$ é tangente a uma elipse $E$, se $r \cap E$ contém apenas um ponto, $T$, chamado ponto de tangência. 


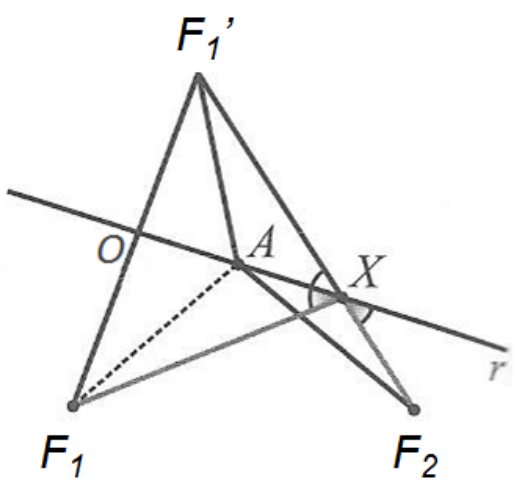

A reta $r$ é então mediatriz de $F_{1} F_{1}^{\prime}$. Logo, como os triângulos $O F_{1} X$ e $O F_{1}^{\prime} X$ são congruentes, temos que: $d\left(X, F_{1}\right)=d\left(X, F_{1}^{\prime}\right)$ e também $d\left(A, F_{1}\right)=d\left(A, F_{1}^{\prime}\right)$. E como por construção, a reta $r$ tem ângulos iguais com $X F_{1}$ e $X F_{2}$ e, pela simetria, os ângulos $A X F_{1}$ e $A X F_{1}^{\prime}$ são também iguais. Daí, os segmentos $X F_{2}$ e $X F_{1}^{\prime}$ fazem ângulos iguais com $r$ e, portanto, os pontos $F_{1}^{\prime}, X$ e $F_{2}$ são colineares.

Sendo assim, usando a desigualdade triângular:

$$
\begin{aligned}
k & =d\left(X, F_{1}\right)+d\left(X, F_{2}\right)=d\left(X, F_{1}^{\prime}\right)+d\left(X, F_{2}\right) \\
& =d\left(F_{1}^{\prime}, F_{2}\right)<d\left(A, F_{1}^{\prime}\right)+d\left(A, F_{2}\right)=d\left(A, F_{1}\right)+d\left(A, F_{2}\right),
\end{aligned}
$$

portanto $d\left(A, F_{1}\right)+d\left(A, F_{2}\right)>k$, o que mostra que $A \notin E$. Concluímos que $X$ é o único ponto de $r$ que pertence à elipse, o que mostra que essa reta é tangente em $\mathrm{X}$ a essa elipse.

No que segue vamos apresentar aplicações do Teorema 5.

\subsubsection{Movimento dos Planetas}

A primeira Lei de Kepler (1571-1630) sobre movimento dos planetas no nosso Sistema Solar diz que os mesmos seguem trajetórias elípticas, no qual o Sol encontra-se posicionado em um de seus focos. Também para que Isaac Newton (1643-1727) pudesse desenvolver sua famosa Lei de Gravitação Universal seu conhecimento sobre cônicas com certeza era bem vasto.

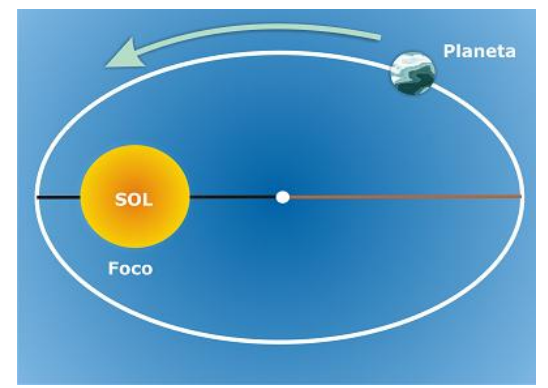

Figura 22 - Movimento Elíptico dos Planetas 


\subsubsection{Aparelhos na área da saúde}

A elipse também está presente na área de saúde humana, onde os espelhos refletores usados pelos dentistas tem formato elíptico. Este consiste num espelho com a forma de um arco de elipse e numa lâmpada que se coloca no foco mais próximo. A luz da lâmpada é concentrada através do espelho no outro foco, que é ajustado pelo dentista para estar num ponto dentro da boca de seu paciente. Assim como os aparelhos utilizados em tratamentos radioterápicos, principalmente contra o câncer.

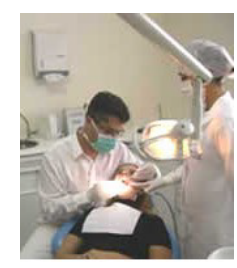

Figura 23 - Espelho Elíptico

\subsection{Espelho Hiperbólico}

Nesta secção, como nas anteriores, vamos apresentar um resultado central envolvendo espelhos hiperbólicos (Teorema 6) e apresentar aplicações que decorrem deste resultado.

Teorema 6. Um raio incidente direcionado a um dos focos de um espelho hiperbólico, reflete em direção ao outro foco do espelho.

Demonstração: Provaremos que a bissetriz do ângulo $F_{1} P F_{2}$ (figura abaixo), em que $F_{1}$ e $F_{2}$ são os focos da hipérbole, é a reta tangente à hipérbole em $\mathrm{P}^{3}$. Uma vez provado isto, o resultado segue como mostraremos a seguir. Para tanto, consideremos que a bissetriz e a tangente sejam a mesma reta. Tome $G \in F_{1} P$ e $B$ um ponto qualquer da bissetriz, tal que $F_{2} G \perp B P$ e

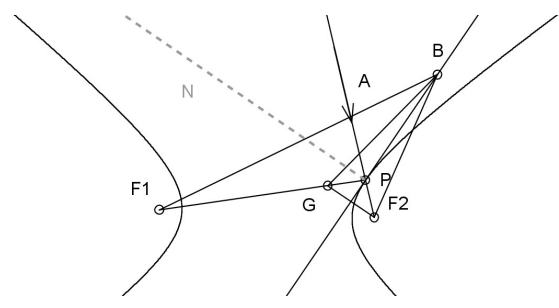

$B P \perp N P$

( $N$ é a reta normal), donde $N P$ e $F_{2} G$ são retas paralelas e o triângulo $P G F_{2}$ é isósceles. Assim, os ângulos desse triângulo em $G$ e $F_{2}$ são iguais. Mas o ângulo em $F_{2}$ é igual ao ângulo de incidência em $A P N$, pois são correspondentes; e o ângulo em $G$ é igual ao ângulo $N P F_{1}$, pois são alternos internos. Logo $A P N=N P F_{1}$. O que demonstra o que queríamos, já que segundo a

3 Uma reta $r$ é tangente a uma hipérbole $H$, se $r$ não é paralela a nenhuma das assíntotas e $r \cap H$ contém apenas um ponto, $T$, chamado ponto de tangência. 
lei de reflexão, o ângulo de incidência é igual ao ângulo de reflexão. Mostremos agora que $B P$ é ao mesmo tempo bissetriz e tangente à hipérbole em $P$.

De fato, pela desigualdade triângular, temos que $d\left(B, F_{1}\right)<d(B, G)+d\left(G, F_{1}\right)$ portanto, $d\left(B, F_{1}\right)-$ $d\left(B, F_{2}\right)<d(B, G)+d\left(G, F_{1}\right)-d\left(B, F_{2}\right)$; mas como $B G F_{2}$ é isósceles, tem-se $d(B, G)=d\left(B, F_{2}\right)$. Portanto,

$$
d\left(B, F_{1}\right)-d\left(B, F_{2}\right)<d\left(G, F_{1}\right)=d\left(P, F_{1}\right)-d(P, G)=d\left(P, F_{1}\right)-d\left(P, F_{2}\right)=2 a,
$$

o que mostra que $\mathrm{B}$ não pertence à hipérbole. Em outras palavras, a bissetriz $B P$ só toca a hipérbole em $\mathrm{P}$, mostrando assim que $B P$ também é tangente à hipérbole.

A seguir veremos uma aplicação do Teorema 6.

\subsubsection{Telescópios}

A hipérbole tem importante aplicação na tecnologia dos telescópios. O primeiro cientista a construir um foi Galileu Galilei (1564-1642) (telescópio refrator), modelo aperfeiçoado por Isaac Newton e finalmente com a tecnologia do espelho hiperbólico, em 1672, pelo astrônomo francês Cassegrain (1629-1693) chegou a sua forma atual (telescópio refletor). O telescópio refletor nada mais é do que um espelho parabólico no fundo de um tubo. Os raios provenientes de um corpo celeste distante (estrela, galáxia, planeta,etc.) formam um feixe praticamente paralelo, que se reflete no espelho e vai formar a imagem do objeto no foco F. O problema agora é que, para observar essa imagem, o observador teria de estar com seu olho no foco da parábola, mas isso é impossível na prática. Em 1672 o astrônomo francês Cassegrain propôs a utilização de um espelho hiperbólico. Um dos focos da hipérbole coincide com o foco $F$ da parábola. Agora

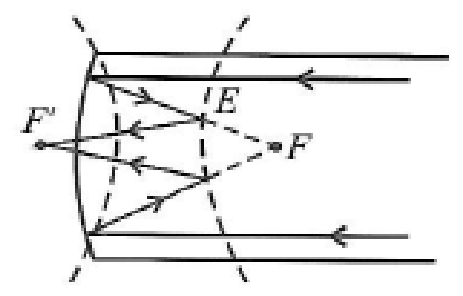

Figura 24 - Telescópio refletor

os raios que iriam formar a imagem no foco $F$ são refletidos pelo espelho $E$ e formarão essa imagem no outro foco $F^{\prime}$ da hipérbole.

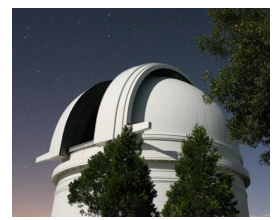

Figura 25 - Observatório Monte Palomar (EUA) 


\section{PROPOSTA PEDAGÓGICA VIA PROJETO}

Este último capítulo apresenta uma proposta pedagógica para o estudo das cônicas: parábola, elipse, hipérbole e propriedades das mesmas. Inicialmente, serão usadas algumas luminárias para atrair a atenção dos alunos e iniciar o estudo dos objetos parabólicos. Posteriormente será apresentado um projeto, que é a elaboração, feita pelos alunos, de uma mesa em formato elíptico. Com a mesa os alunos poderão ver as propriedades da elipse e depois verificá-las e entendê-las matematicamente. Por fim, será feito um estudo das hipérboles e suas aplicações. No estudo das três cônicas os alunos farão a construção geométrica de maneira prática, seguindo a referência (LENZ, 2014), para uma melhor compreensão e entendimento de suas formas.

Esta proposta é aconselhada a alunos da terceira série do ensino médio, pois é o ano em que normalmente estuda-se cônicas e estima-se um tempo de 10 aulas de 50 minutos para sua realização. Acreditamos que essa abordagem seja empolgante e motivadora para os alunos, já que eles verão na prática, como a matemática pode ser aplicada no cotidiano.

Para introduzir o assunto, sugere-se uma roda de conversa para averiguar o conhecimento prévio dos alunos a respeito dessas cônicas, se eles tem alguma noção do que são, de seus formatos, aplicações ou de aparições na natureza.

\subsection{Estudo das Parábolas}

Espera-se que os alunos já tenham estudado função do segundo grau, e assim trabalhado com parábolas, mesmo que de maneira não muito aprofundada, pois iniciaremos dizendo que a parábola é uma curva cônica, e que assim como ela, a elipse e a hipérbole também são.

\subsubsection{Motivação com luminárias}

Em seguida, serão apresentados para os alunos alguns modelos de luminárias, onde pelo menos uma delas tenha o formato parabólico (quanto mais exemplos melhor, com um mínimo 
de três luminárias). É aconselhado que essa apresentação seja feita em algum lugar escuro, para que o aluno veja com maior nitidez de que maneira cada luminária clareia o ambiente.

Figura 26 - Exemplo de Luminária 1

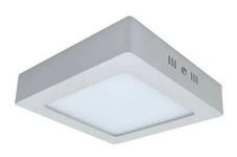

Figura 27 - Exemplo de Luminária 2

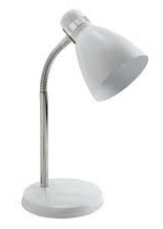

Figura 28 - Exemplo de Luminária 3

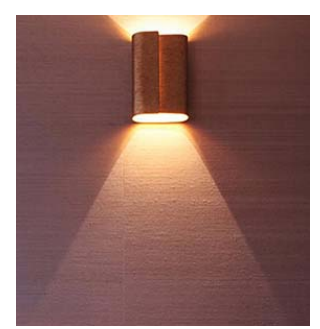

Figura 29 - Exemplo de Luminária 4

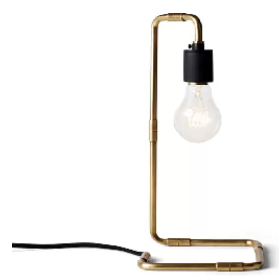

Enquanto os alunos observam as luminárias acesas, o professor pode fazer algumas perguntas para direcionar os alunos, como por exemplo: De que maneira cada luminária clareia o ambiente? Qual das luminárias tem a sua luminosidade mais concentrada? Por quê?

É esperado que os alunos cheguem a conclusão que a luminária que tem sua iluminação mais concentrada seja a da luminária 2. Provavelmente vão associar sua forma de iluminação ao seu formato, porém talvez seja necessário a ajuda do professor para que eles verifiquem que é um formato próximo ao de um parabolóide (nesse momento deverá ser explicado também que o parabolóide é um sólido de revolução, gerado a partir da revolução de uma parábola sob o seu eixo de simetria). 


\subsubsection{Construção geométrica segundo a definição}

A partir do momento em que os alunos associaram o formato de iluminação concentrado com o formato de parábola, será apresentada a definição geométrica de uma parábola (Definição 12 na subseção 3.2.1). Com a definição em mãos, para que eles tenham mais clareza na associação do formato das parábolas com a definição, será proposta a confecção e utilização de um parabológrafo. Será necessário régua, esquadro, uma prancheta, um pino e um fio de comprimento $f$, comprimento igual ao de um dos catetos do esquadro ( $M N$ na figura abaixo). Nesse cateto escolha o vértice do ângulo agudo e prenda uma das pontas do fio. Fixe o pino na posição em que deseja o foco $F$ e prenda a ele a outra ponta do fio.

Figura 30 - Parabológrafo

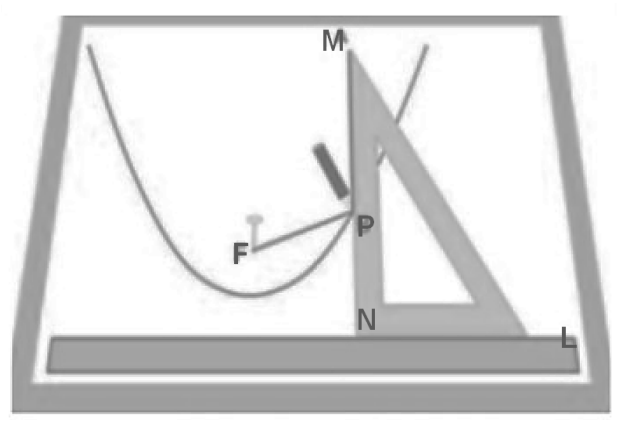

Desenhe a diretriz $L$, à distância $2 p$ de $F, \operatorname{com} p<f$ de maneira a contrução ser viável. Apoiando o outro cateto na régua fixada sobre a diretriz, use a ponta do lápis para manter o fio esticado. Deslizando o esquadro sobre a régua, a ponta do lápis descreverá uma parábola.

Se $P$ é a posição do lápis, então:

$$
d(P, F)=f-d(P, M)=d(N, M)-d(P, M)=d(P, N)=d(P, L)
$$

Logo, $P$ é um ponto da parábola.

Observação 3. A partir da definição geométrica, o professor também poderá deduzir junto com os alunos a equação reduzida da parábola no plano cartesiano (dedução feita na subseção 3.2.1). Na sequência, fixa-se os parâmetros envolvidos e determina-se alguns pontos no plano cartesiano que satisfaçam a equação. Por fim, observar que a representação gráfica destes pontos simulam uma parábola.

\subsubsection{Propriedades e aplicações da Parábola}

Após a apresentação da definição geométrica e da representação gráfica da parábola, o professor discutirá o Teorema 4, para que os alunos entendam a razão do formato parabólico da luminária resultar na maior concentração de luz, e por fim mostrar as aplicações que a parábola nos proporcionam, como por exemplo, farol de carro, e outros descritos na seção 4.2. 


\subsection{Estudo das Elipses}

Com os alunos motivados com as formas parabólicas, inicia-se o estudo das elipses. Pode-se retomar a roda de conversa feita no início do projeto para relembrar o que foi falado sobre elipse. Em seguida apresenta-se a definição geométrica da elipse (Definição 13 na secção 3.2.2) para iniciar o ponto central do projeto que é a elaboração da mesa de bilhar mágica, seguindo a referência (SOUZA, 2008).

\subsubsection{Construção geométrica segundo a definição}

Para facilitar o entendimento da definição, com o auxílio de barbante, isopor, folhas e tarraxas, será pedido que os alunos desenhem elipses nas folhas apoiadas sobre o isopor. As tarraxas farão o papel dos focos e o barbante, que será cortado em pedaços diferentes para cada aluno, representará a soma das distâncias de um ponto da Elipse aos focos.

Figura 31 - Elaboração da Elipse

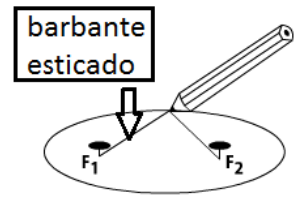

\subsubsection{Projeto mesa de bilhar mágica}

É esperado que, no início, as elipses desenhadas pelos alunos não fiquem muito precisas, mas que com algumas tentativas já fiquem melhores. Após a verificação de que os alunos estão desenhando elipses mais precisas, os mesmos serão divididos em grupos pequenos, de 4 ou 5 alunos, para a confecção do projeto: Mesa de Bilhar Mágica, que nada mais é do que a elaboração de uma mesa de bilhar com o formato elíptico.

O projeto consiste em que cada grupo faça uma mesa de bilhar mágica. Para isso será necessário que cada grupo tenha inicialmente 2 tarraxas, um pedaço de barbante e um pedaço de madeira plano. Cada grupo desenhará uma elipse no seu pedaço de madeira. Posteriormente, essas madeiras serão levadas a um marcineiro que cortará as madeiras nos formatos desenhados. Cobriremos essas madeiras com um pano de algodão verde, como os das mesas bilhar, e também com madeira, ou algum MDF. Faremos em volta da madeira uma parede contornando a elipse, que garanta uma rebatida precisa de uma bolinha após bater na parede.

Feito isso, em um dos focos será feito um buraco na madeira, como se fosse uma caçapa, e no outro foco, uma marcação a tinta. Assim a mesa de bilhar mágica estará pronta, de maneira que um aluno, ao posicionar a bolinha na marca e jogá-la em qualquer direção, a bolinha rebaterá na parede e cairá na caçapa. É fundamental frisar para os alunos que façam o projeto com o 
máximo de precisão possível, para que o experimento de que a bolinha sempre cairá na caçapa ocorra bem.

Figura 32 - Mesa de Bilhar Mágica

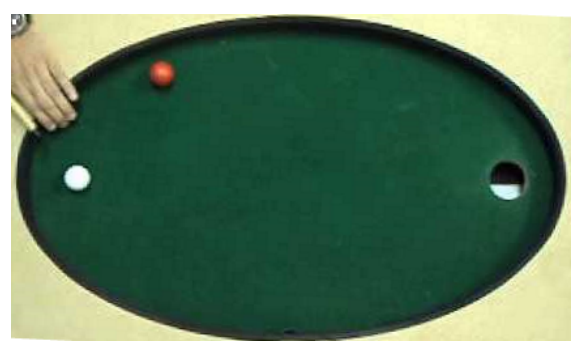

\subsubsection{Explicação Matemática e Aplicações}

Após a finalização do experimento e a verificação visual de que ele ocorreu corretamente, espera-se que isso motive os alunos a se perguntarem qual a razão do fenômeno se repetir, ou seja, porque independente da direção que ele jogue, a bolinha bate na parede, rebate e cai na caçapa.

Figura 33 - Demonstração do experimento: Mesa de Bilhar Mágica

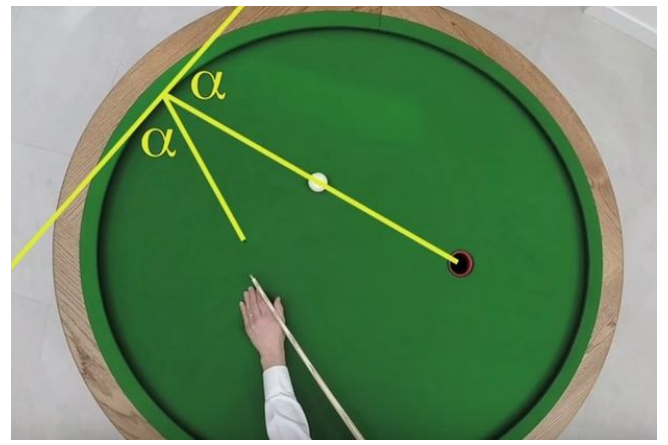

Nesse momento usaremos o que foi descrito na seção 4.3 para provar matematicamente a propriedade da elipse (Teorema 5), que faz com que o experimento se concretize. Finaliza-se o estudo de espelhos elípticos falando de alguns exemplos práticos como por exemplo: espelhos de dentistas e aparelhos de radioterapia, também citados na seção 4.3. Graças a estas propriedades, no espelho dos dentistas, a forma elíptica faz com que os raios de luz se concentrem no dente a ser tratado, facilitando a visualização pelo dentista e evitando o desconforto do paciente de ser ofuscado pelo feixe de luz. Por sua vez, nos tratamentos radioterápicos, células doentes são eliminadas enquanto células sadias ao seu redor não são afetadas.

Observação 4. Pode-se lançar para os alunos o seguinte desafio: Qual é o lançamento correto para a bolinha cair na caçapa, rebatendo antes na parede, caso ela esteja fora do foco?

Espera-se que após alguns lançamentos, somados ao conhecimento que já adiquiriram, os alunos percebam que o lançamento que realiza o desafio, nada mais é, do que uma extensão 
da propriedade já vista, basta jogar a bolinha no ponto onde a reta formada pelo foco e a posição atual da bolinha intercepta com a parede. Conforme na figura abaixo, onde os focos são os pontos preto e branco. A caçapa está no ponto preto. A bolinha é ponto vermelho. Analisando a situação notamos onde deve ser lançada a bolinha para solucionar o problema.

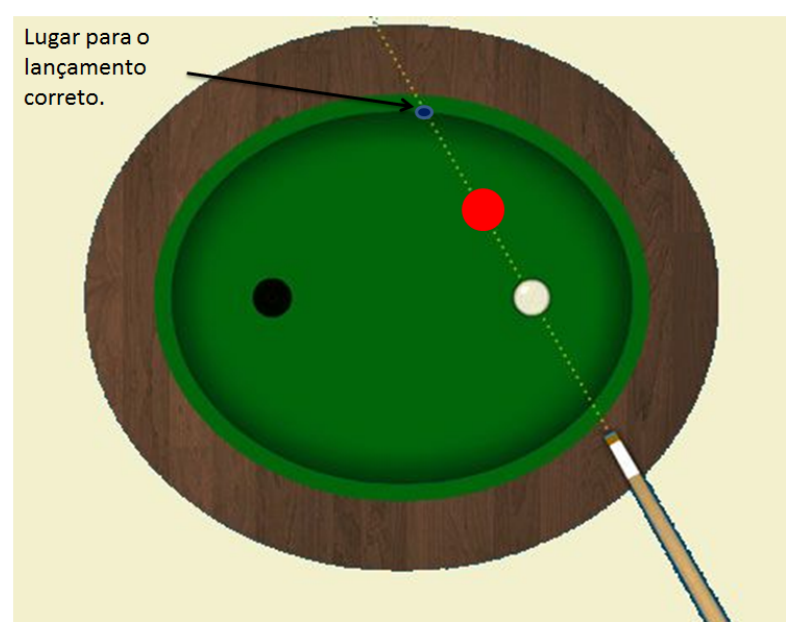

\subsection{Estudo das Hipérboles}

Para finalizar o projeto vamos considerar os espelhos hiperbólicos. Retoma-se mais uma vez a roda de conversa inicial para averiguar se eles tem noção de formato e aplicações. Posteriormente apresenta-se a definição geométrica da hipérbole (Definição 14 na seção 3.2.3).

\subsubsection{Construção geométrica segundo a definição}

Com a definição em mãos, os alunos construirão um hiperbológrafo para uma melhor compreensão da definição e do formato geométrico das hipérboles. Será necessário uma prancheta, dois pino, um fio de comprimento $f$ e uma base rígida de comprimento $h=f+2 a$, articulada por uma das extremidades por um pino a fim de que ela gire em torno dele. Uma das pontas do fio é fixada no outro pino e à extremidade livre da haste (extremidade A na figura abaixo). Os pinos ( $F_{1}$ e $F_{2}$ na figura) são os focos da elipse a ser produzida.

Figura 34 - Hiperbológrafo

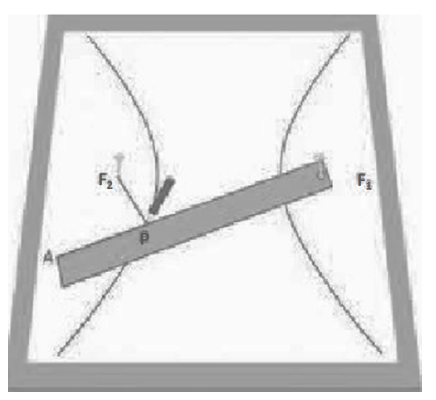


Fazendo a ponta do lápis correr pelo papel mantendo o fio sempre esticado será encontrado um trecho de um dos ramos da hipérbole. Para obter um trecho do outro ramo, articule a haste do pino $F_{2}$ e prenda o fio a $F_{1}$, ou utilize a simetria da hipérbole. Esse método verifica-se pois, sendo $P$ um ponto da hipérbole, temos

$$
\left|d\left(P, F_{1}\right)-d\left(P, F_{2}\right)\right|=|(h-d(A, P))-(f-d(A, P))|=|h-f|=2 a .
$$

Logo, $P$ é um ponto da hipérbole.

\subsubsection{Propriedades e aplicações da Hipérbole}

Após a apresentação da definição geométrica e da visualização da representação gráfica da hipérbole, o professor discutirá o Teorema 6, para que posteriormente, mostre como as propriedades da hipérbole podem ser aplicadas como por exemplo a um telescópio (como descrito na seção 4.4). 

BARBOSA, J. L. Geometria Plana Euclidiana. Fortaleza: SBM, 1995. Citado nas páginas 21 e 28.

COURROL, L. C.; PRETO, A. de O. Apostila Teórica-Óptica Técnica I. São Paulo, 2016. Citado na página 43.

DELGADO, J.; FRENSEL, K.; CRISSAFF, L. Geometria Analítica. Rio de Janeiro: SBM, 2013. Citado na página 33.

LENZ, M. O Estudo das Cônicas a partir da Construção Geométrica. Dissertação (Mestrado) - Universidade Estadual Paulista, Instituto de Geociências e Ciências Exatas, Rio Claro, 2014. Citado na página 51.

MACHADO, M. T. G. Parábolas - As curvas preciosas. Monografia (Programa de Desenvolvimento Educacional) - Universidade Estadual de Londrina, Londrina, 2007. Citado na página 45 .

SOUZA, E. W. de. Cônicas e Aplicações. Monografia (Especialização em Matemática) Universidade Federal de Minas Gerais, Belo Horizonte, 2008. Citado na página 54.

VALLADARES, R. J. C. Elipses, sorrisos e sussuros. Revista do Professor de Matemática, v. 36, 1998. Citado na página 43.

WAGNER, E. Por que as antenas são parabólicas? Revista do Professor de Matemática, v. 33, 1997. Citado na página 43.

ÁVILA, G. A hipérbole e os telescópios. Revista do Professor de Matemática, v. 34, 1997. Citado na página 43. 


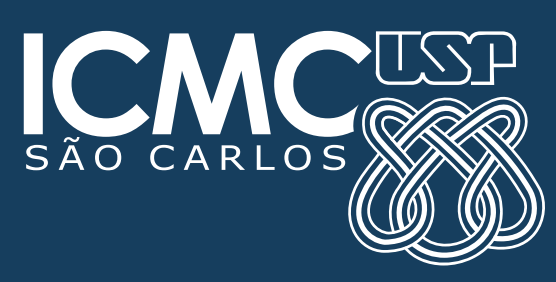

